Martín-Arroyo Sánchez, D. J. y Remesal Rodríguez, J. (2018): “Modelado geográfico de

la agricultura romana. Vegetación de ribera y viticultura en Hasta Regia", Spal 27.1: 211-235. DOI: http://dx.doi.org/10.12795/spal.2018i27.08

\title{
MODELADO GEOGRÁFICO DE LA AGRICULTURA ROMANA. VEGETACIÓN DE RIBERA Y VITICULTURA EN HASTA REGIA
}

\author{
GEOGRAPHICAL MODELLING OF ROMAN AGRICULTURE. RIPARIAN \\ VEGETATION AND VITICULTURE IN HASTA REGIA
}

\author{
DANIEL J. MARTIIN-ARROYO SÁNCHEZ \\ Investigador postdoctoral EPNet. CEIPAC, Facultad de Geografía e Historia, Universidad de Barcelona, \\ c/ Montalegre, 6, 08001, Barcelona. \\ Correo-e: martin-arroyo@ub.edu. ORCID: http://orcid.org/0000-0003-2790-941X \\ JOSÉ REMESAL RODRÍGUEZ \\ Catedrático de Historia Antigua. Investigador principal EPNet. CEIPAC, Facultad de Geografía e Historia, Universidad de Barcelona, \\ c/ Montalegre, 6, 08001, Barcelona. \\ Correo-e: remesal@ub.edu. ORCID: http://orcid.org/0000-0003-1474-3123
}

Resumen: En un marco teórico, los sistemas de conducción de las vides se consideran antiguos legados culturales. Historiográficamente se ha asumido la diferencia entre viticultura de tradición púnica sine pedamentis (sin soportes) e itálica cum pedamentis (con soportes). En este trabajo se explora tal asunción a través del modelado SIG de la ratio agronómica riparia/uinea en la frontera de la colonia Hasta Regia y el municipium de Gades. Esta ratio se fundamenta en el precepto de Columela sobre la proporción entre los viñedos y los espacios ribereños requeridos para proveer materia prima para la conducción de las vides. En esta ocasión se prueba un nuevo enfoque en relación a la autosuficiencia de las fincas.

Palabras clave: modelo, Sistemas de Información Geográfica (SIG), Arqueología espacial, colonización, patrón de asentamiento.
Abstract: In a theoretical framework, vine training systems are considered as an ancient cultural heritage. Historiography has assumed the difference between Punic sine pedamentis and Italic cum pedamentis viticulture. In this paper, exploration of such an assumption is conducted in GIS by modelling the riparia/uinea agronomical ratio in the frontier of the colonia Hasta Regia and the municipium of Gades. This ratio is based on Columella's standard of the proportion between vineyards and riparian spaces required to provide raw material for a vine training system. Now, a new approach on the self-sufficiency of plots is tested.

Keywords: model, Geographic Information Systems (GIS), Spatial Archaeology, colonization, settlement pattern.
Una primera versión de este trabajo se expuso en la 26th Theoretical Roman Archaeology Conference (Sapienza Università di Roma,
16-19 de marzo de 2016). Los resultados de dicha intervención se han reservado exclusivamente para la presente publicación. 


\section{INTRODUCCIÓN}

La explotación romana de la vegetación ribereña es un tema poco habitual en el ámbito de los estudios territoriales. Sin embargo, la importancia ambiental y paisajística de esta actividad pudo tener notables consecuencias en la Antigüedad. Por ello se ha abierto una línea de investigación que cuenta ya con varias publicaciones precedentes. En cada una de ellas se han avanzado enfoques literarios y bibliográficos, acompañados por descripciones de las distintas fases de desarrollo de un caso de estudio SIG. En la primera de ellas se expuso la relación de las sociedades mediterráneas antiguas con las plantas y espacios ribereños según la describen los textos clásicos. Se profundizó entonces en cuestiones tales como la alimentación de personas y ganados, prácticas habituales que se reiterarían con un efecto considerable en la configuración de los paisajes (Martín-Arroyo y Trapero 2015: 243-260). En un segundo momento se tomó la ratio riparia/uinea como enfoque más específico, que planteaba unos parámetros concretos para un caso de explotación vitícola. Se trataba entonces de la práctica del emparrado como exponente de una actividad agrícola con un peso destacado en la economía romana (Martín-Arroyo 2016). En un tercer trabajo se ha planteado el contexto provincial del caso de estudio SIG, resaltando los escasos datos disponibles sobre los derivados de la uva en la Baetica. Esta rama productiva debió ser importante, pero quizás haya pasado desapercibida por razones propias de la configuración del registro arqueológico, tales como el uso polivalente de las ánforas. Así pues, los tipos anfóricos se han asociado genéricamente al aceite, el vino o las salsas de pescado. Sin embargo, como demuestra particularmente la epigrafía documentada sobre estos objetos, algunos tipos se usaron como contenedores de distintas clases de alimentos. Tanto estas particularidades del registro arqueológico, como la problemática general que cuestiona la viabilidad del modelado como método, confluyen en el caso de estudio aquí tratado (Martín et al. 2017: 205-208 y 216-218). En una futura publicación, el modelo SIG se extenderá a 225 yacimientos para potenciar el análisis comparativo entre diferentes contextos cívicos y geográficos (MartínArroyo y Castro en prensa).

En esta ocasión se pretende reforzar el cumplimiento de los objetivos iniciales: despertar el interés de la comunidad científica sobre este tipo de estudios e implementar la metodología disponible. Más concretamente, se define una serie de parámetros que completa el modelo SIG. Para ello se delimita el potencial vitícola del área de estudio conforme lo requeriría el autoabastecimiento de las fincas rústicas que la habrían ocupado. Así pues, se supone que el tamaño y la disposición topográfica de las parcelas rústicas procurarían la inclusión de espacios ribereños suficientes para abastecer los viñedos emparrados. Dicha propensión respondería al interés económico prioritario otorgado por la mentalidad romana hacia una viticultura de este tipo. No obstante, la práctica del emparrado también sería una cuestión cultural, entendida como un uso consuetudinario. El cultivo sine pedamentis tendría que delatar una tradición púnica, ubicada hacia la costa y perteneciente al municipium de Gades (Cádiz). Hacia el interior, la implantación de la vid cum pedamentis sería un legado itálico propio de colonias como Hasta Regia (Jerez de la Frontera). La divergencia entre municipium y colonia estaría condicionada por bases poblacionales diferentes. En Gades buena parte de su población tendría un remoto origen fenicio-púnico. En Hasta Regia la inmigración itálica previa y la propia deductio de la colonia a partir del 45 a.C. habrían configurado un sustrato cultural diferente. Por tanto, aunque las dos ciudades estarían muy romanizadas en torno a los inicios del Imperio, sus idiosincrasias propias podrían manifestarse en sistemas de cultivo que afectaran a sus respectivos patrones de asentamiento rural. La dedicación que requiere la viticultura favorecería una ocupación más estable del campo, generando asentamientos que dejaran mayor peso en el registro arqueológico. Si la viticultura se practicó bajo los requisitos del cultivo cum pedamentis, esto se plasmaría en la distribución de la ocupación, concentrándose donde la riparia estuviera disponible y espaciándose en otras zonas. Estas y otras características se tratarán de poner en evidencia a través del modelado SIG de un espacio geográfico de contacto entre ambas ciudades y su registro arqueológico.

\section{MARCO TEÓRICO E HISTORIOGRÁFICO}

La obra de K.D. White (White 1975: 19-23) contiene un apartado dedicado a la terminología sobre los soportes de la vid en la literatura clásica. Se distinguen dos grupos de conceptos, según se aluda a un soporte simple o compuesto por varios elementos vegetales, entre otras muchas consideraciones aplicables. El término pedamentum estaría en el primer grupo, pero se utiliza en este trabajo con carácter genérico para referirse al conjunto de la estructura de conducción de la vid, por lo que se ha declinado en plural. Sin embargo, la estructura en estudio a partir de la ratio dada por Columela 
(Col. 4.30.2) correspondería a un conjunto compuesto por elementos verticales, horizontales y atadura ( «pedaminum ingorumque et uiminum»)(Col. 4.30.1):

...Salicum viminalium (ut Atticus putat) singula iugera sufficere possunt quinis et vigenis iugeribus ligandae vineae; arundineti singula ingera vigenis iugandis; castaneti iugerum totidem palandis, quot arundineti iugandis (Col. 4.30.2).

...Ático considera que una yugada de mimbreras puede bastar para atar veinticinco yugadas de viña; una de cañaveral, para formar los soportes de veinte; y que una de castañar da para rodrigar el mismo número de yugadas de viña que la de cañaveral abastece de soportes (trad. García 2004: 354).

Otra fuente para el estudio de la conducción de vides en el mundo romano es la iconográfica, cuyos soportes más frecuentes son los mosaicos y sarcófagos (Blázquez 1996: 518; García-Gelabert y García-Gelabert 2009-2010: 213-214). Las estructuras elevadas se representan claramente en los mosaicos africanos, mientras que las escaleras incitan a pensar en tales soportes para algunos casos hispanos, como en el mosaico de la pisa de la uva en Emerita Augusta (Mérida, España). Debe considerarse también la representación de vides "arbustivas", maridadas a árboles, como en el caso de un mosaico de Deir el-Adas (Siria) (Blázquez 1996: tav. VII y IX, 2). Cabría plantear al respecto la relación entre la distribución geográfica de estos soportes iconográficos y la práctica de la conducción de vides en tales zonas. En cualquier caso y por lo que concierne al presente trabajo, debe remarcarse su presencia fuera de Italia, particularmente en suelo hispano.

También el mosaico de los Trabajos (aux Travaux) de Saint-Romain-en-Gal (Ródano-Alpes, Francia) muestra una escena de vendimia con vides emparradas, asociada a otras del proceso de vinificación. En la misma zona, la villa romana de Goiffieux en SaintLaurent-d'Agny ha deparado unas zanjas de plantación (sulci) asociadas a huellas de postes. Su interpretación apunta a la existencia de una vid compluviata o iugata en una zona ajardinada, produciendo para el abastecimiento de la villa. La estructura y métrica de las zanjas de plantación remiten a modelos itálicos de finales de la República e inicios del Imperio. Esta y otras evidencias apuntan hacia una fase de adaptación de técnicas itálicas (40-20 a.C.) a las condiciones del territorio, tras la fundación de la colonia de Lugdunum (Lyon) (Poux et al. 2011: 41-45 y 91). Algunas estructuras de irrigación y drenaje de Goiffieux, además de las propias zanjas de plantación, recuerdan la problemática de la asociación de la viticultura con la bonificación de suelos (MartínArroyo 2010).

Este tema se manifiesta en el contexto históricogeográfico de los restos de un hipotético emparrado hallado en Gevrey-Chambertin (Côte-d'Or, Francia). En este caso las huellas de postes se asocian a fosas de plantación (aluei), cuya métrica se ha contrastado con la información dada al respecto por los agrónomos latinos. La secuencia estratigráfica y los materiales asociados ofrecen una datación de finales del siglo I y primera mitad del II d.C. Este viñedo antiguo se asentó sobre una llanura relativamente húmeda, al igual que otros documentados en el mediodía francés, la región parisina e Inglaterra. La ubicación de los viñedos se desplazó hacia zonas de pendiente a finales del siglo III d.C. o en los decenios siguientes (Garcia 2011: 100110). Por último, debe destacarse la significativa presencia de monocotiledóneas, asimilables a las cañas (Arundo/Phragmites), en el registro arqueobotánico de distintos pozos de granjas galorromanas de la Francia meridional. Los usos artesanales de estas especies eran muchos. Se han asociado también a la protección contra la erosión de las aguas y la incidencia de los vientos sobre los cultivos. No obstante, teniendo en cuenta la estrecha asociación con el periodo romano y los procesos de vinificación documentados en las granjas, se han propuesto empleos tales como la elaboración de elementos para el prensado de la uva, de soportes de las vides jóvenes o de armazones del tipo de la uitis characata (Figueiral y Séjalon 2010: 146 y 148; Figueiral et al. 2014: 33 y 35-36). Este tipo de conducción es citada por Columela entre los tipos provinciales. Las cepas se enredarían en una serie de cañas clavadas alrededor de las mismas (Col. 5.4.1). Esta composición podría responder a la representada en el mosaico de Tabarka (Blázquez 1996: tav. II; García-Gelabert y García-Gelabert 2009-2010: 217). No obstante, otros soportes provinciales como el iugum de la uitis canteriata podrían haber requerido también el empleo de cañas.

El historiador A. Tchernia (1986) dividió la geografía del viñedo romano según su conducción en dos zonas, definidas a partir de los testimonios de los agrónomos latinos. Las viñas altas contarían con árboles o emparrados y serían propias de la península itálica. Las viñas bajas se darían en Hispania, entre otros lugares, según el testimonio de Varrón:

Contra vineam sunt qui putent sumptu fructum devorare. Refert, inquam, quod genus vineae sit, quod sunt multae species eius. Aliae enim humiles ac 
sine ridicis, ut in Hispania, aliae sublimes, quae appellantur iugatae, ut pleraeque in Italia. Cuius generis nomina duo, pedamenta et iuga. Quibus stat rectis vinea, dicuntur pedamenta; quae transversa iunguntur, inga: ab eo quoque vineae ingatae (Var. R. 1.8.1).

Al contrario, los hay que piensan que la viña se traga el beneficio con el coste. Importa, digo yo, de qué tipo de viña se trate, porque las hay de muchas clases. Unas son bajas y sin tutores, como en Hispania; otras altas, que se llaman yugadas, como sobre todo en Italia. En este tipo se usan dos nombres, "tutores" y "yugos". A los soportes rectos en que se apoya la vid se los llama "tutores"; los que unen transversalmente, "yugos": de ahí lo de viñas yugadas (trad. Cubero 2010: 70).

Este agrónomo solo aludió a un tipo de viña baja en su obra: la rampante. Columela (Col. 5.4.1; Col. Arb. 4.1) y Plinio (Plin. Nat. 18.164) las dividieron sin embargo entre rampantes y en vaso. En las provincias romanas no desconocerían la práctica del emparrado, aunque el cultivo sine pedamentis sería lo más común. El presunto origen púnico de la poda en vaso reforzaría la idea de su implantación en la Baetica, entre otros indicios dentro de la obra de Columela:

[1] Vites maxime gaudent arboribus, quia naturaliter in sublime procedunt, tunc et materias ampliores creant et fructum aequaliter percoquunt. Hoc genus vitium arbustivum vocamus, de quo pluribus suo loco dicemus. Vinearum autem fere genera in usu tria sunt, ingata, humi proiecta et deindetertia, <quae> est a Poenis usurpata, more arborum in se consistens. Id genus conparatum iugatae quadam parte deficitur, quadam superat. [2] Ingata plus aeris recipit et altius fructum fertet aequalius concoquit, sed difficilior est eius cultus; at haec ita constituta est, ut etiam arari possit, eoque ubertatem maiorem consequitur, quod saepiuset minore inpensa excolitur. At quae protinus in terram porrecta est, multum, sed non bonae notae vinum facit... (Col. Arb. 4.1-2).

[1] La vid como más a gusto se encuentra es con los árboles, porque por su natural tiende a trepar; así maridada, cría más madera y madura por igual el fruto. Llamamos «arbustiva» a esta clase de vides, y de ella hablaremos por extenso en su momento. Por otro lado, podemos decir que están en uso tres clases de viñas: la "de yugo", la que se extiende por el suelo, y luego una tercera, utilizada por los cartagineses, que se sostiene por si sola al modo de los árboles. Esta clase, si la comparamos con la emparrada, es inferior a ella en algún aspecto, superándola en algún otro. [2] La de yugo está más aireada y trae el fruto más alto y lo madura más por igual, pero su cultivo es más difícil; la otra, en cambio, está dispuesta de tal forma que incluso puede ararse, y alcanza así mayor rendimiento, al dársele mayor número de labores y con menor gasto. En cuanto a la que se desparrama sobre el mismo suelo, produce mucho vino, pero no de buena calidad...(trad. García 2004: 87).

Continuando con este discurso, A. Tchernia recoge los testimonios literarios sobre los costes del emparrado con especial referencia al pasaje de Julio Ático que, conocido a partir de Columela (Col. 4.30.2), sirve de base a la ratio riparia/uinea. Añade a estas referencias otras que provienen del registro epigráfico y ciertos paralelos históricos. En definitiva, este autor afirmó que en época de Augusto, el viñedo provincial sine pedamentis tendría cierta ventaja económica sobre el viñedo cum pedamentis itálico. Particularmente, estimó ventajosa la poda en vaso tarraconense y bética (Tchernia 1986: 179-184).

La historiografía posterior no avanza demasiado sobre esta perspectiva (Sáez 1995: 21-22; Martín 2015), existiendo un consenso generalizado y faltando particular interés en esta temática. Simplemente cabe alegar un par de sugerencias al respecto. La primera de ellas incidiría en la perspectiva sesgada que ofrecen las fuentes literarias, siendo conveniente prestar una mayor atención al creciente número de evidencias arqueológicas, concretamente a las fosas de plantación de viñedo que puedan ir acompañadas de vestigios de emparrado. En segundo lugar, el testimonio de Varrón para Hispania se sitúa en una cronología previa a lo que pudo ser el inicio de una implantación del viñedo itálico. Un fenómeno que podría haberse visto fomentado por la colonización, tanto por el asentamiento de nuevos pobladores tras las guerras civiles como por la regularización de los conuentus ciuium Romanorum preexistentes. Se sumaría a continuación una fuerte transformación económica, derivada de la extensión del sistema de la uilla y de otros factores favorables que condujeron a la municipalización flavia de las comunidades hispanas. Todo ello hace cuestionar el peso de la viticultura cum pedamentis en zonas similares a la que se recoge en el caso de estudio de este trabajo.

Otra cuestión de interés para el presente trabajo viene dada por la credibilidad de las cifras ofrecidas por los agrónomos latinos, fundamentalmente por Columela. Estas cifras serán la base del modelo planteado tanto en los datos relativos a la ratio riparia/uinea como en el cálculo de unidades de producción agraria sostenibles. El latinista R. Martin estimó las cifras relativas al tipo ideal de las explotaciones columelianas a partir de un profundo conocimiento de la agronomía 
latina. Este autor diferenció la explotación columeliana respecto al concepto actual de "latifundio", siendo la primera de dimensiones razonables y estando sujeta a una puesta en valor intensiva (Martin 1971: 344-349). La propiedad ideal columeliana contaría con saucedas y cañaverales en las zonas llanas y bosques para la producción de pedamenta en las colinas (Col. 1.2.3-4). Se explotaría con mano de obra esclava, pues el arrendamiento era menos rentable y se debía limitar a ciertos casos. R. Martin llegó a calificar de utópica la obra de Columela (Martin 1971: 366) en tanto que procuraba la adaptación del sistema de explotación catoniano, entre otras condiciones ideales. En efecto, la extensión media de las propiedades, vistas como unidades de explotación, habría variado de las 50-100 ha en el imaginario de Catón hasta las 500-1500 ha en el de Columela. El número de esclavos necesarios habría ascendido paralelamente de los 15-20 a los 200. Estas diferencias trascenderían de lo cuantitativo a lo cualitativo. El sistema habría resultado caro y complejo de administrar, lo que forzaría paulatinamente a la imposición del colonato como modo de explotación (Martin 1971: 350356). Por otro lado, la defensa que Columela hace de la viticultura como actividad rentable parece coincidir con el desarrollo posterior de este cultivo (Martin 1971: 370-373). Por tanto, al menos una parte de su mensaje coincidiría con las tendencias agronómicas que efectivamente se acabaron implantando en su época.

Una exploración más intensa de la totalidad de las cifras dadas por Columela se encuentra en la obra del historiador R. Duncan-Jones. Se tienen en cuentan costes de materiales, infraestructuras y mano de obra, así como periodos de amortización y otras cuestiones relativas a precios y mercados (Duncan-Jones 1974: 3959). Entre sus cálculos se incluye una reflexión sobre los costes de preparación del viñedo (Duncan-Jones 1974: 52-54). Finalmente, su visión redunda en la incoherencia de las cifras dadas por Columela, sometidas a múltiples variantes y difíciles de combinar con datos de otras épocas (Duncan-Jones 1974: 55 y 327-333). Esta incoherencia se restringe por el propio consejo agronómico de actuar empíricamente y adoptar los usos del vecindario o la región (Var. R. 1.18.7-8; Plin. Nat. 17.170). Además, según R. Duncan-Jones, el modelo columeliano sería seguido por viticultores que constataban o esperaban una alta rentabilidad de sus producciones, dada por su volumen o por la calidad del vino (Duncan-Jones 1974: 57). Esto supone que los preceptos de Columela se aplicarían a un limitado porcentaje de los viñedos romanos, lo que explicaría la excepcionalidad de las cifras dadas por el autor.
En definitiva, valorando las aportaciones de R. Martin y R. Duncan-Jones, se podría apostar por el desarrollo de modelos que buscaran la coherencia de los datos agronómicos latinos en comparación con otros datos históricos vinculables a un espacio determinado. Fijar la atención sobre una variante concreta, entre las muchas que pueden configurar el modelo, también es conveniente para afrontar la investigación positivamente. Esto permitiría solventar paulatinamente cuestiones simples, como la correcta conversión de las unidades de medida. No es indispensable y quizás tampoco sea posible partir de una completa integración de todos los datos cuantitativos disponibles a partir de la agronomía latina, como lo hizo R. Duncan-Jones. Una visión generalista como la presentada por R. Martin es necesaria para la detección de los fenómenos históricos subyacentes. Pero, por otro lado, la modelización puede efectuarse sin necesidad de asumir disyuntivas insuperables a priori, como la implantación romana del sistema esclavista o del colonato en el marco de estudio seleccionado.

\section{CASO DE ESTUDIO}

\subsection{Objetivo y documentación del caso de estudio}

Este trabajo continúa un modelado SIG cuyas primeras fases de trabajo se han detallado en publicaciones precedentes (Martín-Arroyo y Trapero 2015: 251-257; Martín-Arroyo 2016; Martín et al. 2017: 216-218. Véase también el espacio descrito en Trapero y Mata, 2016). Con ello se han establecido ciertas bases para modelar la aplicación de un principio agronómico latino (Col. 4.30.2) en un contexto hipotético basado en datos históricos y geográficos.

El modelado GIS reproduce la complejidad de un escenario, un espacio en el que tiene lugar una prolongada actividad humana; en este caso, un entorno rural de época romana. Las limitaciones de la información disponible para ello determinan el carácter hipotético del contexto. La variabilidad de los valores aplicados en la definición de los elementos que configuran el modelo ofrece un repertorio de escenarios posibles. Mediante el modelado se hacen explícitas las asunciones que el investigador realiza al reflexionar sobre un fenómeno, haciendo patente su verosimilitud o denunciando sus debilidades. El caso práctico que se propone busca una exploración epistemológica de este tipo en relación con la Historia Agraria del mundo romano. Por otro lado, el desarrollo de un modelo con tal finalidad es un objetivo 
metodológico en sí mismo, es decir, la implementación de la herramienta necesaria para llevar a cabo estas consideraciones.

El análisis de un precepto agronómico latino limita la complejidad de la tarea propuesta, centrando la atención sobre un problema mejor acotado. Sin embargo, visto desde una perspectiva más amplia, se trata de un paso hacia la valoración de cuestiones complejas en torno a los propios textos como fuente histórica fundamental. En primer lugar se valora el alcance del imaginario de Columela, su relación con la Baetica, provincia en la que se hallaban sus raíces familiares, precisamente en Gades. En cierta forma se observa el origen y la versatilidad de sus preceptos para estimar la recepción y la adaptación de los mismos por un posible lector antiguo. En segundo lugar, se valoraría cómo encajan ciertas pautas agronómicas en el contexto general de una mentalidad que oscila entre una autosuficiencia conservadora y la especulación con vistas al mercado.

Un último objetivo sería el análisis de la propia documentación arqueológica que sirve de base al modelo. Al mismo tiempo se trata de hacer una aportación a la definición general de patrones de asentamiento en el mundo rural romano. Concretamente, como se ha expuesto con anterioridad, se procura estimar el impacto de un sistema de cultivo determinado en la configuración del registro arqueológico. Para ello se busca la elaboración de un marco en el que explorar la influencia de ciertos factores geográfico-culturales en el desarrollo económico de la conducción de vides.

La documentación seleccionada para el caso de estudio se compuso a partir de un conjunto de yacimientos detectados por prospección en los términos municipales de El Puerto de Santa María y Rota (Cádiz, España). Los distintos enclaves se datan con diversos arcos cronológicos, coincidiendo en activo entre el año 45 a.C. y el 74 d.C. A partir de estos yacimientos se generó una red de polígonos Thiessen que dividía el espacio por el que se distribuyen. Se seleccionaron 73 polígonos que no se veían distorsionados por el "efecto borde de mapa", estando bien definidos por una serie de polígonos circundantes. Se cuantificó la disponibilidad de tierra de labor (no-riparia) y riparia correspondiente a cada yacimiento. Este desglose de las zonas ribereñas y de cultivo se hizo sobre la base del Mapa Alemán 1940-1944, que cumplía ciertos requisitos de definición de los espacios representados, escala y estado poco industrializado de la agricultura en la zona.

\subsection{Objetivo del presente trabajo}

En esta ocasión se propone un avance teórico-metodológico del modelo SIG comentado. Este consistirá en la estimación de la posible incidencia de la viña sobre las tierras de labor delimitadas anteriormente. Para ello se realiza una propuesta de estructura ideal de las explotaciones agrarias. Así pues, se caracteriza la proporción de los distintos cultivos en una finca autosuficiente, sostenible según el ideal conservador del pensamiento agronómico latino. El mantenimiento de la mano de obra asociada a tal finca será el punto de partida para la consideración de tal autosuficiencia. Al mismo tiempo, la viña explotada de manera intensiva será el exponente de una posible producción de excedentes. Este capital sobrante podría haberse dedicado a múltiples fines, que cubren diferentes marcos hipotéticos sobre las necesidades de la explotación agraria y el sistema de propiedad imperante.

\subsection{Modelo autosostenible}

Columela indicó que era necesario un viñador para $7 \mathrm{iu}$ gera de viña (Col. 3.3.8). La cifra oscila entre 8 y 10 iugera en otros testimonios agronómicos latinos (Duncan-Jones 1974: 327). Un iugerum equivale a 2.523,3408 $\mathrm{m}^{2}$. Los 7 ingera de viña constituirán la unidad básica de partida, a la que habrá que añadir la tierra cultivable que es necesaria para la manutención de su correspondiente viñador. Se necesitaban 51 modii de trigo para mantener a una persona durante un año. Duncan-Jones (1974: 146-147) estimó la cantidad de 51 modii anuales por esclavo a partir del testimonio de Catón (Cato Agr. 56). El agrónomo ofrecía a los esclavos no encadenados 4 o 4,5 modii de trigo al mes, dependiendo de la temporada. Otros testimonios sobre raciones de trigo de época romana no se ajustan tanto al contexto rural aludido por Catón, pero constatan cifras similares, entre 3 y $5 \mathrm{mo}$ dii. Cinco modii de trigo al mes equivaldrían a 3.0003.500 calorías por día, estimándose una cifra ideal para un hombre adulto de 3.300 calorías por día.

Se puede estimar una producción de 12 modii de trigo por ingerum y año. Columela estimó 4 modii de trigo de siembra por cada ingerum de tierra de buena calidad (Col. 2.9.1) o seca y suelta (Col. 2.9.5). El trigo ofrecería un rendimiento de $3 \times 1$. Esto conlleva una producción de 12 modii por iugerum (Sáez 1987: 7983 y 88-89). Sáez (1987: 89) recogió una noticia sobre una productividad de $4 \times 1$ a partir de Columela (Col. 3.3.4). Esta afirmación del agrónomo latino refiere una 
cifra excepcional, que no recoge la productividad habitual. Además, se alude a la particular fertilidad de los campos ceretanos, que la historiografía reciente sitúa en Caere (Italia) (García 2004: 251, nota 34). Sáez (1987: 88-89) obtuvo la ratio 3 x 1 para los agri Leontini (Sicilia) a partir de un texto de Cicerón (Cic. Ver. 2.3.116), mientras que Plinio (Plin. Nat. 18.95) comparaba la producción obtenida por los Leontini a la que se conseguía en todas las partes de la Baetica.

Por tanto, serían necesarios 4,25 iugera para producir el trigo consumido anualmente por el viñador. Si se incluye el terreno necesario para la producción de semillas para la siguiente cosecha, la cifra asciende a 6,138 iugera. Los 4,25 iugera destinados a trigo para el consumo requieren 4 modii de trigo cada uno. Los $17 \mathrm{mo}$ dii de trigo de siembra resultantes se dividen entre los 12 modii que produce cada ingerum, resultando 1,416 iugera (se eliminan los decimales restantes). Estas operaciones se repiten una vez más para calcular el espacio de siembra añadido a los 1,416 iugera, resultando 0,472 iugera. Las operaciones se podrían repetir sucesivamente en este sentido, pero la continuación de estos cálculos se ha considerado poco relevante para el estudio en curso. Los 4,25 iugera necesarios para la producción de alimento, se suman a los 1,416 y 0,472 iugera necesarios para la producción de semillas, resultando así un total de 6,138 iugera. Estableciendo un sistema de rotación trienal de los cultivos, serían necesarios 18,414 iugera para el mantenimiento de un solo viñador. En su libro II, Columela expuso principios para la siembra de trigo y leguminosas, para el estercolado y para la creación y mantenimiento de prados. El cuidado intensivo de la tierra puede sugerir una rotación bienal. No obstante, la importancia económica de los prados hace optar por el sistema trienal en el caso de estudio propuesto. En un sistema tripartito sería más fácil encajar medidas para la reposición de la tierra (abonado, nitrogenado por plantación de leguminosas, barbecho) con el mantenimiento de una cabaña ganadera mínima, incluyendo la fuerza de trabajo animal necesaria para el trabajo del campo. Sin embargo, algunos indicios apuntan a la aplicación del sistema bienal (año y vez) en la próxima campiña jerezana durante la Baja Edad Media (Martín 2004: 53-55). Los referidos 18,414 iugera de tierra de labor no solo producirían trigo. El sistema de rotación trienal permite el cultivo de leguminosas y el pastoreo de una pequeña cabaña ganadera. Además, el olivo se cultivaba en la Baetica dentro de los propios trigales, añadiendo una producción de olivas y aceite a este marco ideal. Una parte de la producción del viñedo satisfaría igualmente la necesidad de uvas y vino
(Cato Agr. 57-58). Estas consideraciones de Catón sobre la alimentación de los esclavos aparecen comentadas en la obra de Duncan-Jones (1974: 146). La viña y los cultivos de rotación trienal suman 25,414 iugera de tierra de labor.

Para la aplicación de la ratio riparia/uinea de Columela es necesario un espacio añadido de 0,98 iugera por cada 7 iugera de viñedo, equivalente al 14\%. Se compone de un 4\% de mimbreral (0,28 iugera), un 5\% de cañaveral $(0,35$ iugera) y un $5 \%$ de castañar $(0,35$ iugera). El espacio destinado al castañar pasaría al cómputo de la tierra de labor (no-riparia) requerida. De tal forma, esta ascendería a los 25,764 iugera. Probablemente se emplearía el olivo o el acebuche como sustituto en este caso, especies a las que se asigna provisionalmente un espacio equivalente al castañar. El mimbreral y el cañaveral serían cultivos de riparia, es decir, se establecerían en unos espacios asociados a medios húmedos. Estos espacios se han delimitado y medido de manera independiente a la tierra de labor (no-riparia), que ocuparía el espacio restante del área de estudio. En síntesis, la ratio riparia/uinea exigiría una proporción de 0,63 iugera de riparia por cada 25,764 iugera de no-riparia. Esta proporción sirve al establecimiento del Modelo 1.

Los cañaverales se plantarían preferentemente en la riparia pero, en caso de necesidad, podrían cultivarse en la no-riparia (Col. 4.32.1). Por ello se puede establecer una proporción diferente a la anterior. Así pues, a cada 26,114 iugera de no-riparia corresponderían 0,28 iugera de riparia, sembradas exclusivamente de mimbreras. Esta proporción sirve al establecimiento del Modelo 2.

Para representar cartográficamente los resultados de ambos modelos, el tamaño de los símbolos que ubican los yacimientos se ha incrementado en relación a la aplicabilidad de la ratio riparia/uinea (fig. 1). Esta aplicabilidad depende del número mínimo de unidades (NMU) de explotación ideal con las que cuente cada yacimiento en el interior de su polígono Thiessen. Esta cifra es el resultado de dividir los iugera de riparia entre 0,63 y los iugera de no-riparia entre 25,764 para el Modelo 1. Para el Modelo 2 las cifras correspondientes serían 0,28 y 26,114. La menor de las dos cifras resultantes en cada modelo y para cada yacimiento será el número mínimo.

Los resultados de ambos modelos pueden visualizarse conjuntamente, situando los símbolos del Modelo 2 bajo los del Modelo 1. En efecto, el Modelo 1, al exigir una mayor proporción de riparia (mimbres y cañas) ve reducido el número de unidades de explotación 


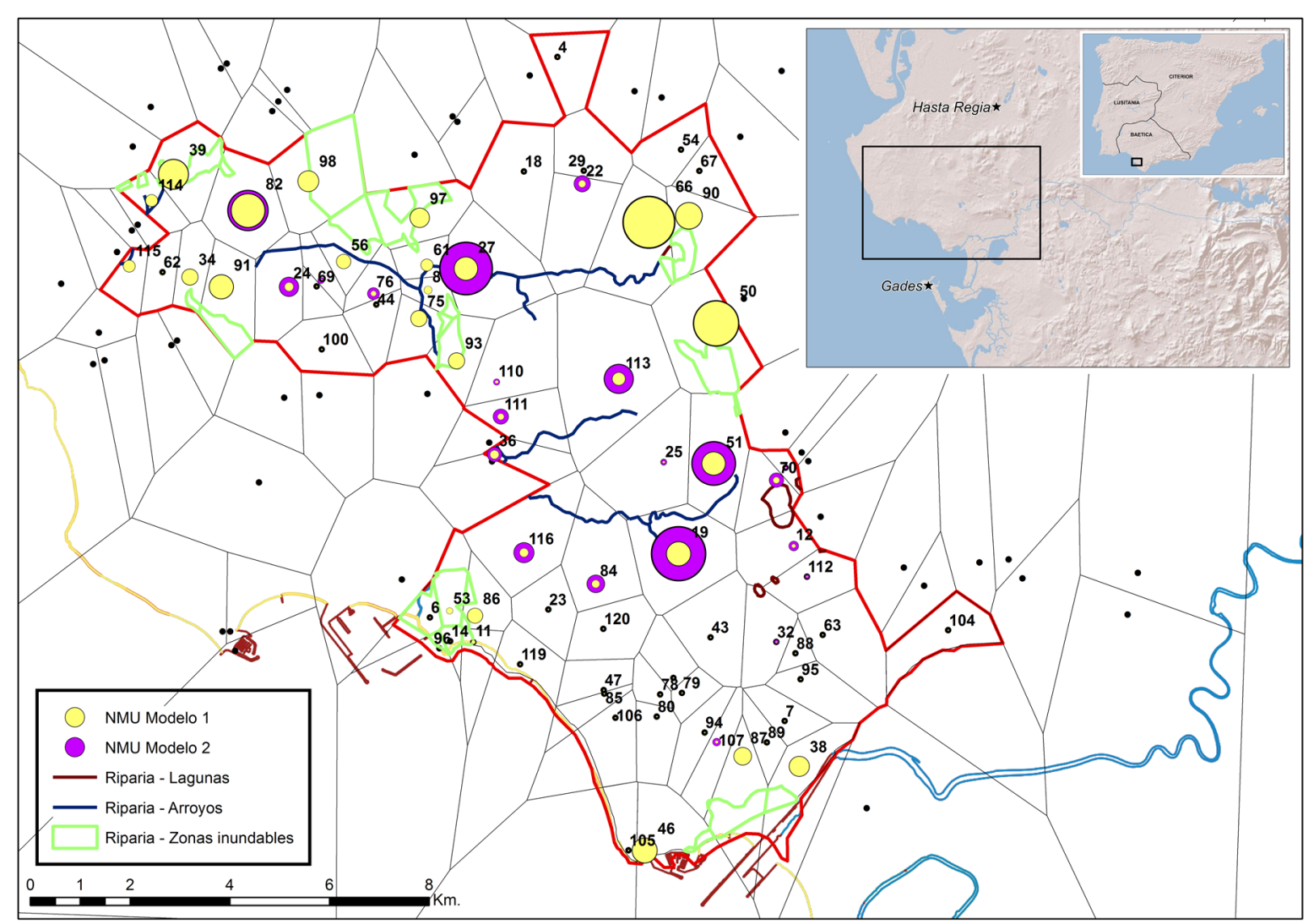

Figura 1. Distribución de la riparia y unidades mínimas de explotación de los Modelos 1 y 2 asociadas a cada yacimiento.

ideal. En algunos casos el número mínimo es igual para ambos modelos, pero los símbolos del Modelo 1 nunca superan en tamaño a los del Modelo 2. Este hecho evidencia que la riparia es el elemento delimitador del número mínimo. La extensión de la no-riparia en algunos polígonos Thiessen da cabida a una mayor cantidad de unidades de explotación ideal cuando la dependencia de la riparia es menor.

\subsection{Análisis del modelado}

Una revisión metodológica del modelado propuesto debe considerar el recurso fundamental a los polígonos Thiessen. La crítica habitual impone la aplicación de criterios que reduzcan la aleatoriedad de los resultados, teniendo en cuenta factores como la topografía, los hallazgos materiales y la jerarquía de los asentamientos (Hodder y Orton 1976: 72; Wheatley y Gillings 2002: 149-151; García Sanjuán 2005: 212-215). Estas medidas se encuentran a su vez limitadas por la configuración del registro, su documentación y los propios enfoques de los estudios espaciales (Ruestes 2006: 229-230; Goodchild 2013: 67-68). En este trabajo, cada yacimiento es considerado como el núcleo de un fundus. Esta unidad de explotación agraria se configuraría a partir de una compleja casuística. A continuación, se valora la conveniencia de aplicar medidas correctoras sobre los polígonos Thiessen empleados en el modelado, distribuyendo alternativamente el terreno.

La topografía del área estudiada no incluye accidentes significativos que impidieran la continuidad de un fundus. Se podría recurrir a la existencia de una centuriación como factor estructural, pero no determinante. Es decir, los caminos (limites) tampoco impedían la continuidad de un fundus (Hyg. Gr. agrim. 204.4-13 La y Fron. agrim 5.16-6.2 Th. en Chouquer y Favory 2001: 154-155. Sobre la sortitio ilicitana: Olesti 2014: 230231) como unidad de explotación, aunque sugieran una tendencia en la configuración del mismo. De hecho, las centuriaciones se utilizaban en las asignationes coloniales para medir el terreno y garantizar el acceso a las 
parcelas. No obstante, se atiende a otros factores como la calidad de los suelos o los diferentes tamaños de los lotes asignados (Sic. fl. agrim. 156.4-17 La; Chouquer y Favory 2001: 153-154), imponiendo discontinuidades en las propiedades resultantes. También la extensión o el fraccionamiento de los fundi en los procesos de apropiación y explotación de la tierra generaría formas irregulares. El estudio de las centuriaciones resulta interesante para la investigación, pero carece de precedentes en el área analizada y requiere una labor crítica que sobrepasa los límites del presente trabajo.

La documentación arqueológica tampoco es suficiente para establecer una rigurosa jerarquía de sitios, que regulara la proporcionalidad o agrupamiento de los polígonos. Estos datos provienen fundamentalmente de un registro de superficie, sin cuantificación y escasamente descrito (ver anexo 1). En la figura 8 se indican las uillae, siendo solo 6 de los 73 yacimientos comprendidos en el área de estudio modelizada. Su acumulación al NE se debe al sistema de catalogación empleado por Ponsich, mientras que en el resto del mapa responde a distintos criterios o alcances de las respectivas publicaciones. Por otro lado, la presencia de una uilla es interpretada aquí como una forma de residencia, ligada a cierto potencial en la apropiación de la tierra. No obstante, la propiedad rústica podía ser discontinua y dividirse en unidades de explotación o granjas. Incluso la uilla contaría como unidad de explotación, sostenida por el uillicus, aunque finalmente se distinguiera en el registro arqueológico como consecuencia de la residencia señorial asociada. Puesto que el modelado se centra en la explotación agraria, la asociación a figlinae resulta más interesante para este trabajo. Muchas de ellas se integraron durante los siglos I a.C. y I d.C. entre las dependencias de los asentamientos rurales estudiados (Lagóstena y Bernal 2004).

Es posible que muchos de estos sitios fueran interdependientes y que compartieran un fundus en ocasiones. Sin embargo, la aplicación de fórmulas de agrupación requiere un estudio propio, que no solo varíe, sino que también reduzca la aleatoriedad en los resultados. Entre tanto, la aplicación de los polígonos Thiessen se considera una forma objetiva de solucionar la distribución de recursos en función de la ocupación del espacio. Así pues, la restitución de este reparto se ve obstaculizada por la incertidumbre en los datos y por las múltiples variables históricas que lo generaron. La configuración de los polígonos Thiessen puede considerarse conveniente frente a la irregularidad de un sistema en el que tanto el fundus como su explotación se adaptarían a múltiples variantes. Se establece de tal forma un reparto promedio de los recursos entre los yacimientos, con cierta proporcionalidad respecto a su distribución. Por otro lado, la estimación Kernel de densidad y su representación cartográfica sirven para valorar la concentración espacial de los yacimientos y sus repercusiones en el modelado (fig. 2).

Para explorar el peso de la riparia y la no-riparia sobre los resultados, se ha aplicado el mismo método de representación cartográfica que se ha utilizado para los modelos. El número de iugera es elevado en ambos casos. Se ha obtenido un tamaño de los iconos adecuado a la escala cartográfica mediante la división de los iugera de riparia entre 2 y de los iugera de no-riparia entre 10. El mapa de los iugera de riparia evidencia una concentración en el sector noroeste del área de estudio (fig. $3)$. Otros focos menores se reparten al noreste, suroeste y sureste. Estas concentraciones son fruto del sistema de medida de la riparia. Las orillas de arroyos y lagunas se miden en buffers de anchura reducida. Martín-Arroyo (2016: 118) estableció una anchura de 5,92 $\mathrm{m}$ por cada orilla a partir de las afirmaciones de Columela (Col. 8.15.5). Por otro lado, las zonas inundables se miden por su extensión completa. Esta diferencia y las necesidades propias de la representación cartográfica hacen que la riparia de arroyos y lagunas desaparezca en gran medida del mapa resultante. Las zonas inundables endorreicas de la mitad norte del área de estudio ofrecen los resultados más visibles. Este efecto se repite en la mitad meridional, donde las zonas inundables pertenecen a las desembocaduras del arroyo Salado al Oeste y del río Guadalete al Este. Debe tenerse en cuenta que diferencias naturales en este segundo grupo de zonas inundables, como la torrencialidad o salinidad de las aguas, pudieron limitar o impedir la implantación de los cultivos de riparia.

El mapa de los iugera de no-riparia muestra una cierta distribución concéntrica (fig. 4). La mayor densidad de la ocupación rural próxima a la costa podría verse como un factor determinante en tal distribución. El paso de la Via Augusta por el extremo sureste de la zona de estudio también podría incidir en este aspecto. El yacimiento de Venta Alta (núm. 113) centraliza esta disposición de la no-riparia de mayor a menor. La extensión de su no-riparia ocupa la práctica totalidad del polígono Thiessen con 2453,52 iugera frente a sus 7,52 iugera de riparia. De hecho, se trata de la única área de no-riparia que se encuentra dentro del rango de tamaño estimado por R. Martin para las fincas columelianas (500-1.500 ha). Si se observan las proporciones dadas por dicho autor para las extensiones de no-riparia asignadas a los yacimientos, se obtienen unos resultados 


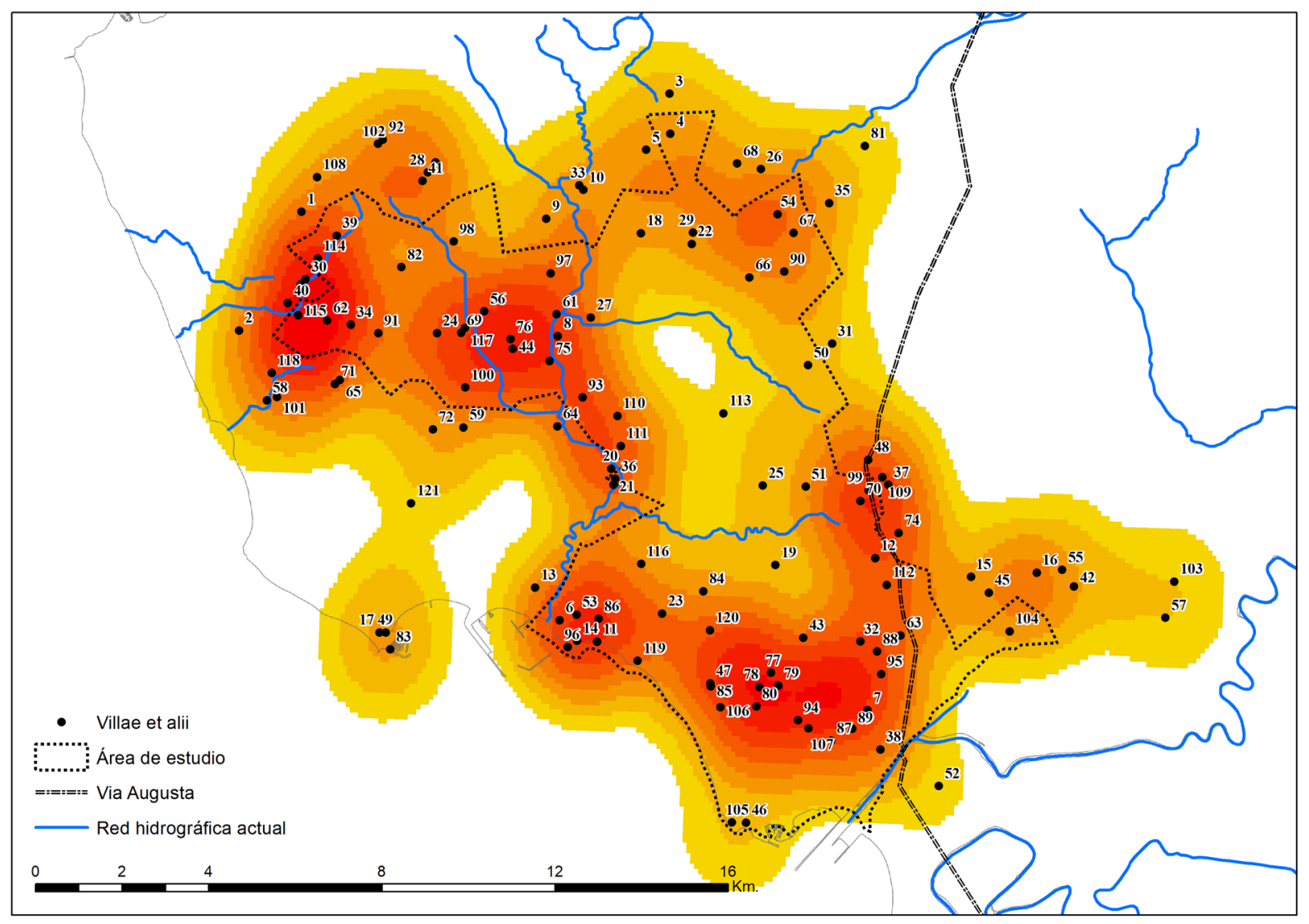

Figura 2. Estimación Kernel de la densidad de yacimientos.

más próximos al ideal catoniano (50-100 ha). Los 73 casos estudiados ofrecen 9 extensiones de terreno menores a 50 ha, 19 entre 50-100, 44 entre $100-500$ y 1 entre 500-1.500. La mayor parte de los casos se encuentra en una franja numérica intermedia entre los tamaños idealizados de R. Martin. La extensión media de la noriparia es de 144,88 ha. Si se considera la posibilidad del drenaje, las fincas que contasen con zonas inundables extensas podrían ganar bastante espacio. No obstante, la relación con las cifras dadas por R. Martin no varía demasiado aunque se sumen riparia y no-riparia, dando la extensión total de los polígonos Thiessen. Así pues, en 6 casos estarían por debajo de las 50 ha, en 17 casos entre 50-100, en 49 entre $100-500$ y en 1 entre 500-1.000. La extensión media de los polígonos Thiessen sería de 157,15 ha.

Se muestran a continuación unos gráficos (figs. 5 y 6) y un cuadro de síntesis (tabla 1) de las cifras resultantes de la modelización para los 73 yacimientos estudiados. Las unidades mínimas de explotación autosuficiente se han agrupado para ofrecer una idea general de la tendencia de las cifras. Se incluyen las unidades mínimas de explotación de la no-riparia como elemento de contraste. Las cifras de no-riparia solo ofrecen ligeras diferencias. El total de unidades de explotación de la no-riparia indica que 1.631 o 1.609 individuos podrían autoabastecerse de alimentos en el área de estudio y cultivar viñedos cum o sine pedamentis. La aplicación de los modelos supone que 572 o 750 personas podrían haberse integrado como trabajadores en unidades de explotación que aplicaran la ratio riparia/uinea. Esta disparidad de cifras se explica en parte por la alta proporción de fincas que no alcanzan a contener una unidad mínima de explotación en los modelos. Las cantidades medias de unidades mínimas de explotación para los iugera de no-riparia y los modelos vuelven a acusar la incidencia de la distribución de la riparia para la aplicación del modelado.

El examen de los resultados debe señalar aquellas zonas cuyo peso en la modelización es muy pequeño o nulo, que contienen menos de una unidad mínima de explotación (fig. 7). Al Sur existe también un conjunto 


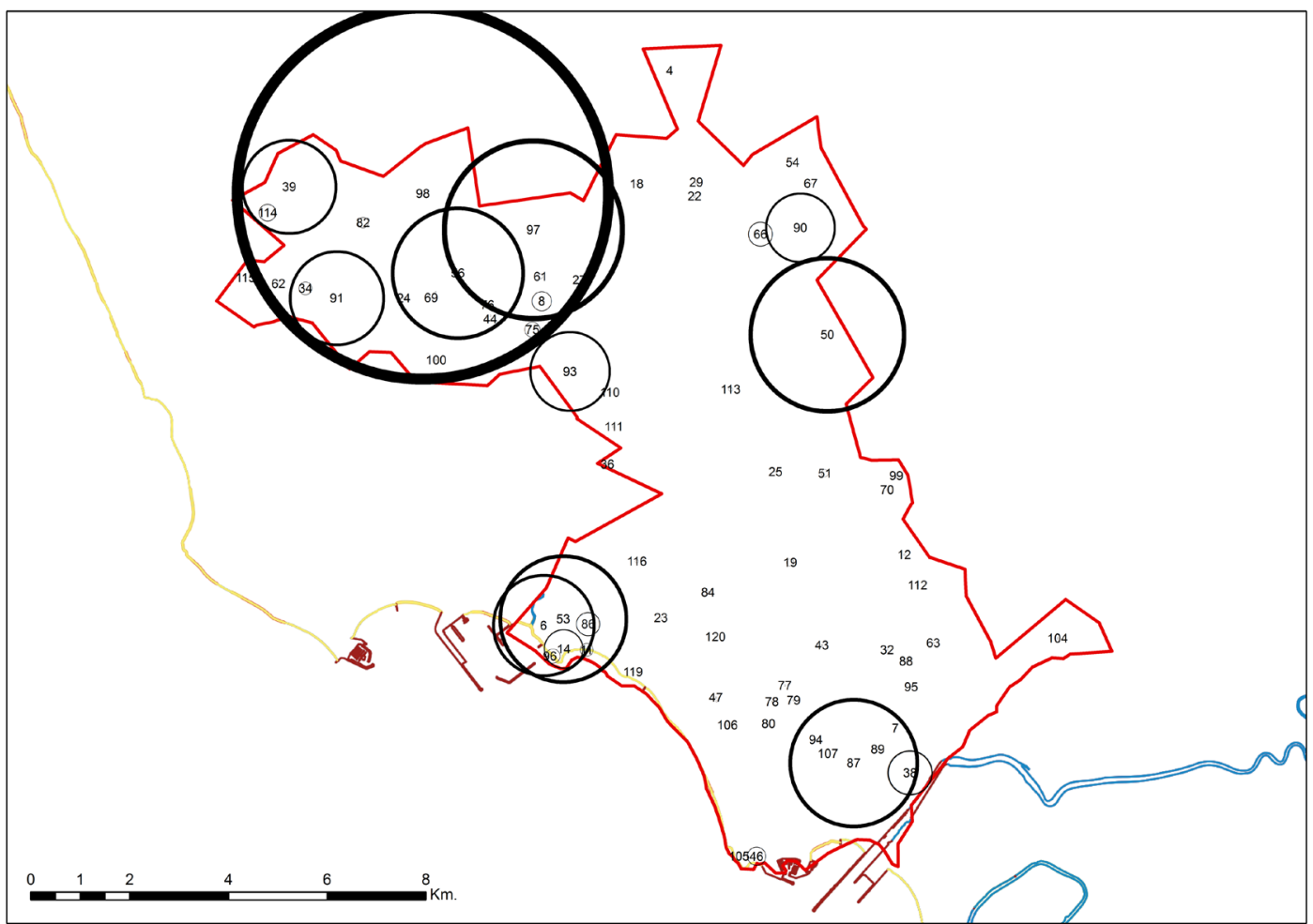

Figura 3. Distribución de la riparia asociada a cada yacimiento.

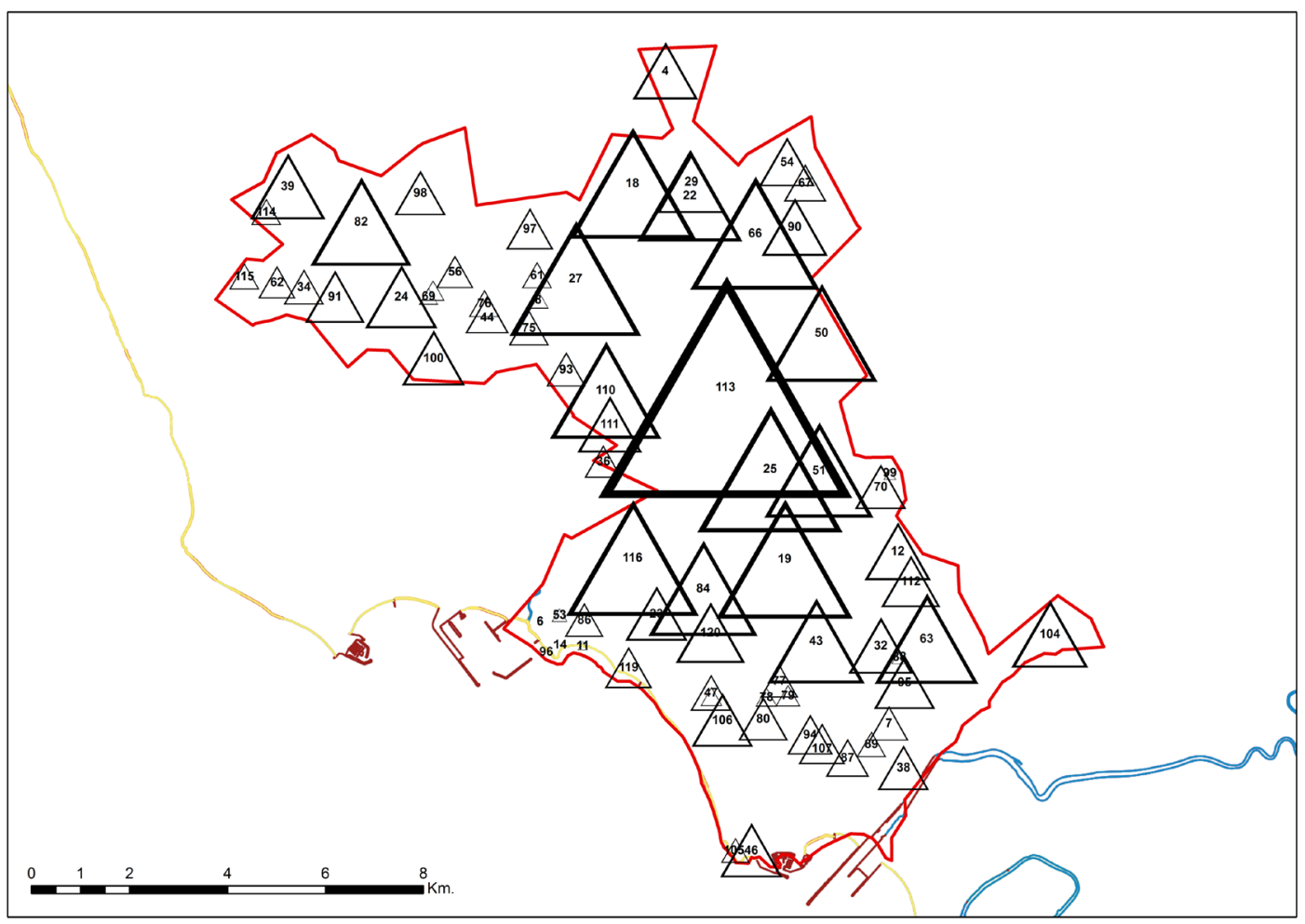

Figura 4. Distribución de la no-riparia asociada a cada yacimiento. 


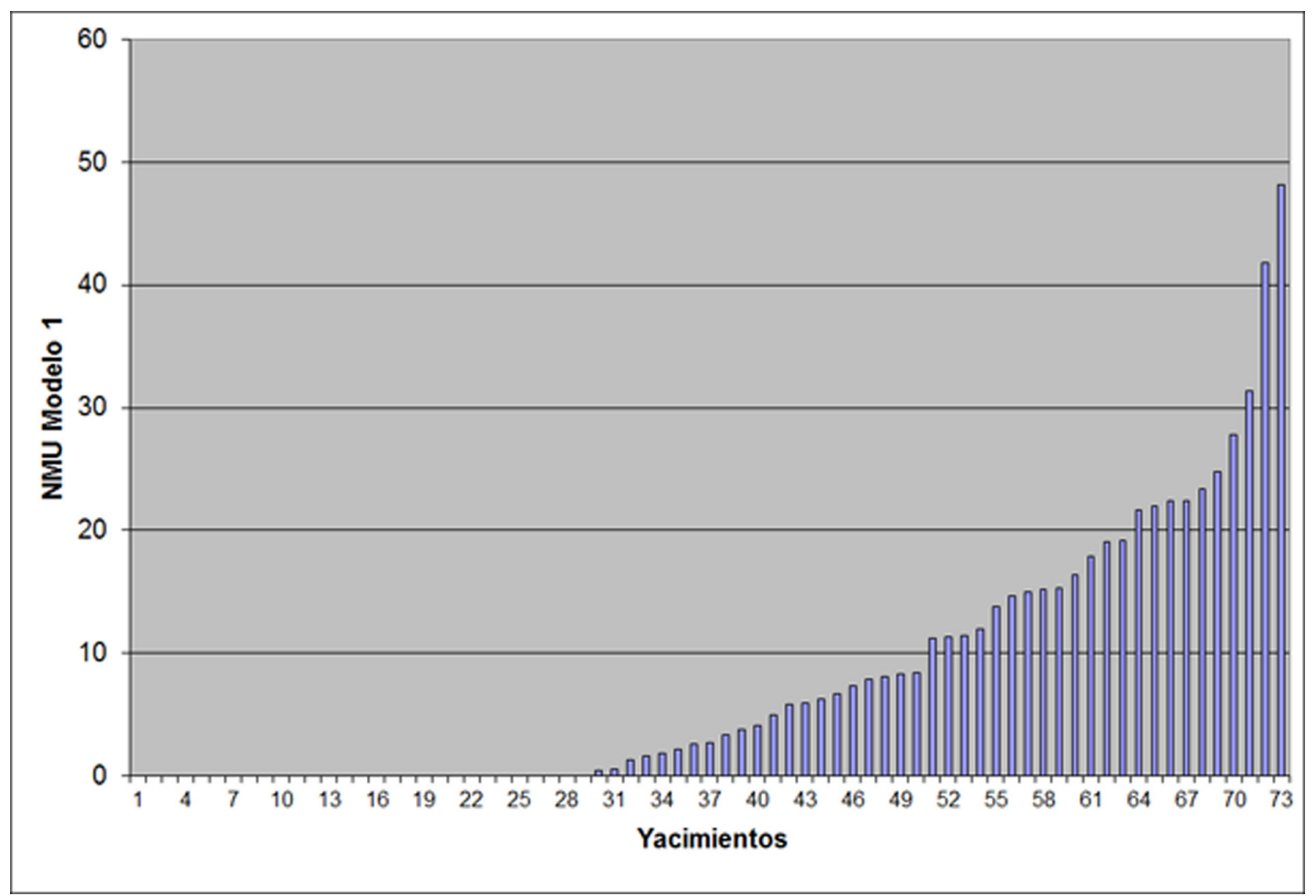

Figura 5. Número mínimo de unidades de explotación en el Modelo 1 de la ratio riparia/uinea.

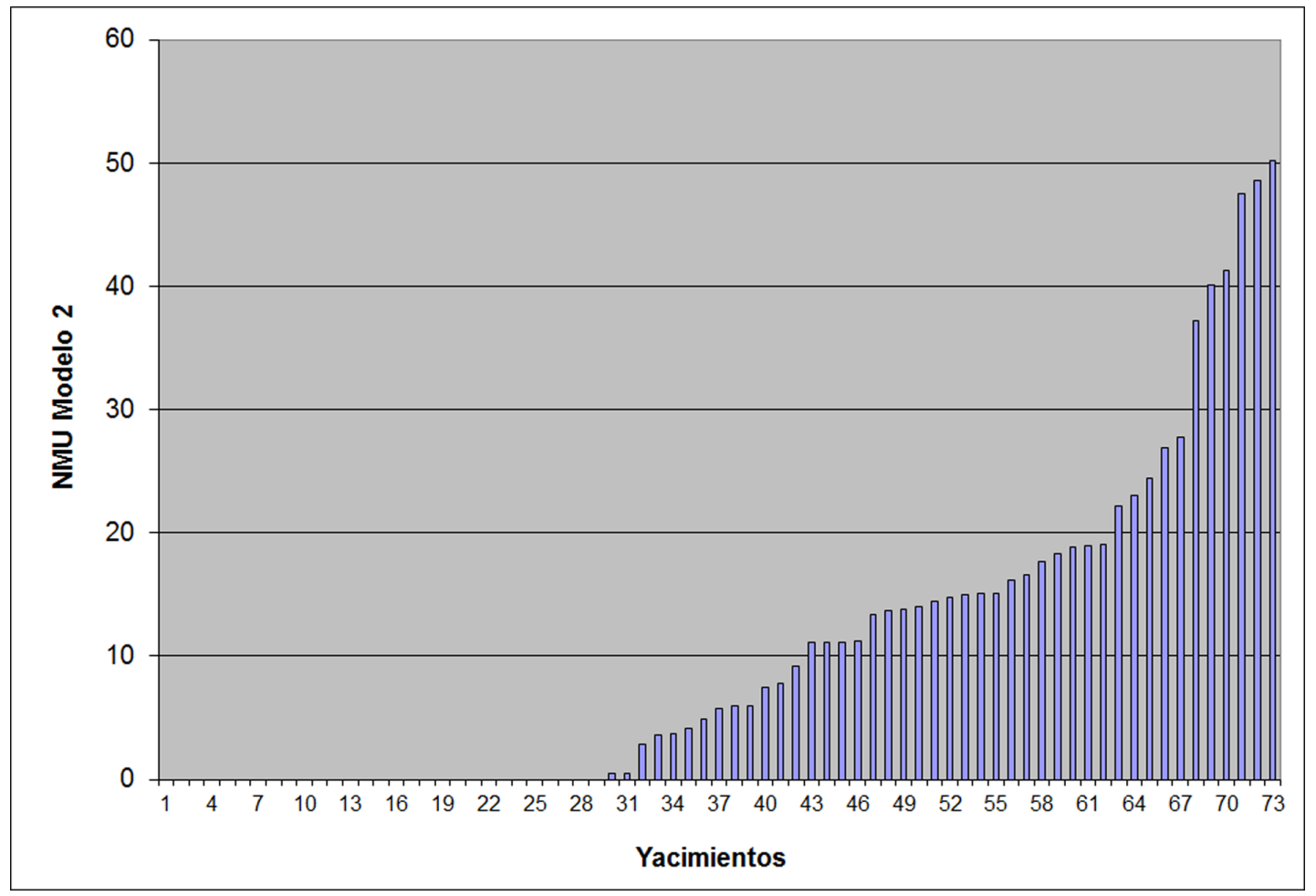

Figura 6. Número mínimo de unidades de explotación en el Modelo 2 de la ratio riparialuinea. 
Tabla 1. Unidades mínimas de explotación en los modelos (M) y unidades mínimas de explotación no-riparia de los modelos.

\begin{tabular}{|c|c|c|c|c|}
\hline Unidades & No-riparia $(\mathrm{M} 1)$ & Modelo 1 (M1) & No-riparia (M2) & Modelo 2 (M2) \\
\hline $0-1$ & 3 & 29 & 3 & 29 \\
\hline $1-10$ & 11 & 20 & 11 & 20 \\
\hline $10-20$ & 26 & 13 & 18 & 6 \\
\hline $20-30$ & 18 & 8 & 4 & 4 \\
\hline $30-40$ & 4 & 1 & 8 & 1 \\
\hline $40-50$ & 8 & 2 & 2 & 0 \\
\hline $50-60$ & 1 & 0 & 1 & 750,95 \\
\hline $60-100$ & $1.631,43$ & 572,35 & $1.609,57$ & 10,28 \\
\hline Total & 22,34 & 7,84 & 22,04 & 4 \\
\hline Media & 2 & 0 & 26 & 12 \\
\hline
\end{tabular}

poco destacado de 4 yacimientos, asociados al área de inundación de la desembocadura del Guadalete. Sobre este espacio deben valorarse cuestiones relativas a los niveles de colmatación, el torrencial y la salinidad de las aguas. La hipotética canalización de la desembocadura del Guadalete para la habilitación del Portus Gaditanus (El Puerto de Santa María) podría haber generado un entorno similar al representado en el mapa de 1940-1944 (López y Pérez 2013: 87-102). En cualquier caso, no se han detectado evidencias de cambios en la red hidrográfica relacionados con la modificación de este tramo del río.

Además, los viticultores pudieron gestionar las especies que proliferaban en estos ámbitos marismeños y adaptar consecuentemente los sistemas de emparrado. Entre las opciones dadas por Columela (Col. 4.13.2) para el atado de las vides, sugiere el «paludibus desectus iuncus, aut ulua». En la traducción de García (2004: 319): «el junco cortado en las marismas o la anea». En este sentido cabe valorar el posible empleo de especies como el Juncus maritimus L. y del Juncus acutus L. (White 1975: 237; véase también André 1985: 134; Segura y Torres 2009: 296-298). El junco se usaba en toda Grecia para atar las vides:

Est quorundam inperitia sub ramo uvitem vinculo suspendendi, suffocante iniuria: contineri debet vimine, non artari (quin immo etiam quibus salices supersunt molliore hoc vinculo facere malunt herbaque
Siculi quam vocant ampelodesmon, Graecia vero universa iunco, cypero, ulva),... (Plin.. Nat. 17.209).

An ignorant way of some growers is to suspend the vine by means of a tie beneath a bough of the tree, a damaging procedure which stifles it, as it ought to be held back with an osier white, not tied tightly (indeed even people who have plenty of willows prefer to do it with a tie softer than the one which these supply, namely with the plant which the Sicilians call by the Greek name "vine-tie", while the whole of Greece uses rush, galingale and sedge);... (trad. Rackham 1971: 145).

Además, el iuncus marinus u oxyschoenon estaba entre las especies tratadas por el cartaginés Magón (Plin. Nat. 21.112), con el referente que esto supone para las tradiciones púnicas relacionadas con el área de estudio. De tal forma, las particularidades del curso bajo del Salado y la desembocadura del Guadalete podrían sustentar un sistema análogo al modelo de la ratio riparia/uinea, en el que los juncos sustituyeran a las mimbreras. Las cañas podían ocupar otros espacios marginales, pero también cabe considerar que fueran sustituidas por los juncos en los sistemas de emparrado. Así pues, la ulua y el palustris iuncus crecidos en las marismas del pueblo germánico de los Chauci se emplearon en la fabricación de cuerdas (Plin. Nat. 16.2-4). A su vez, las cuerdas se utilizaron en la construcción de iuga (Var. R. 1.8.2). 


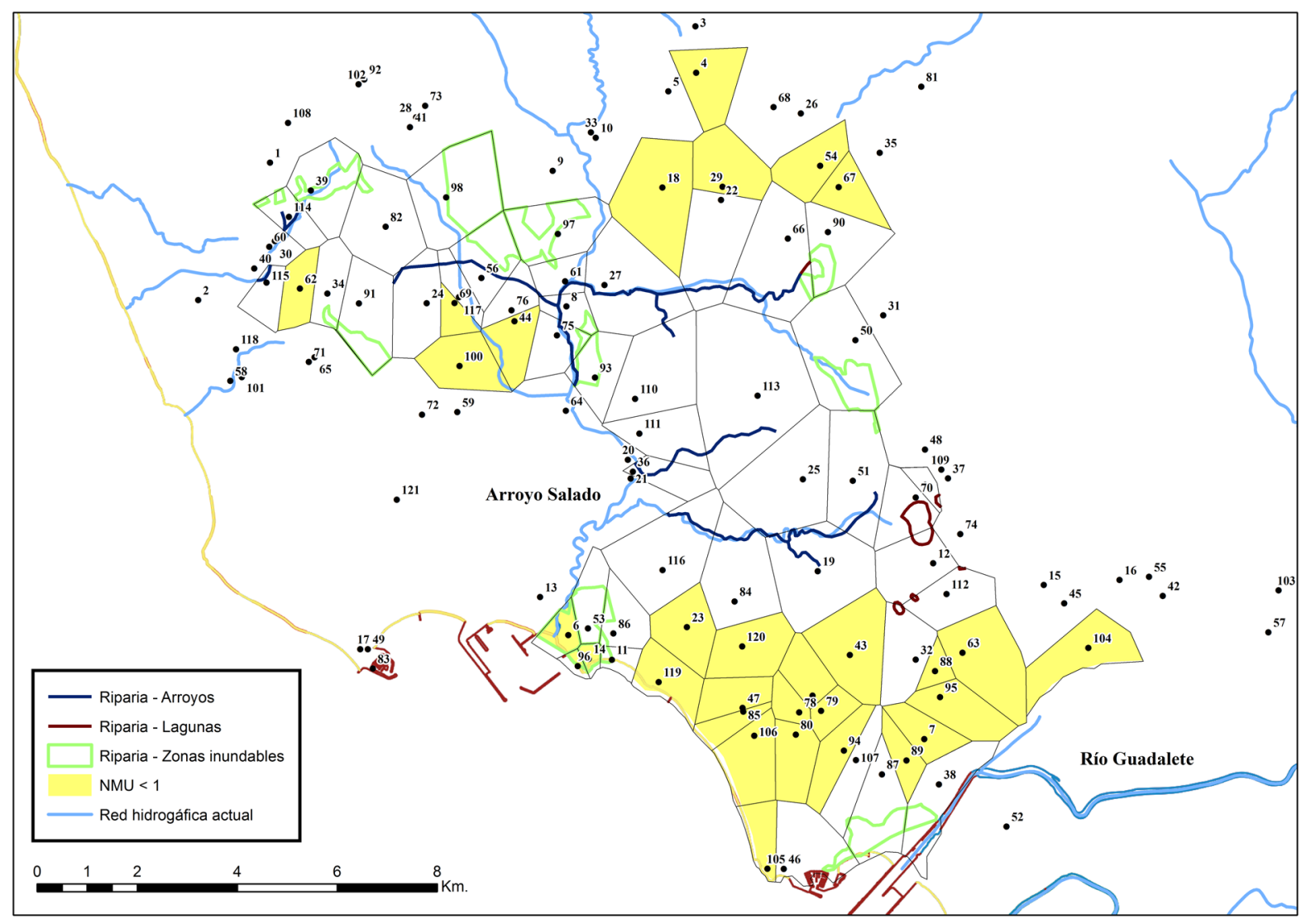

Figura 7. Zonas de incidencia baja o nula del modelado y elementos de la riparia.

Por otro lado, un área más extensa ofrece resultados destacados. Esta coincide en su mayor parte con ciertos elementos de la cuenca de captación y canalización de las aguas que convergen en el arroyo Salado. Como elemento de contraste respecto a los datos extraídos del Mapa Alemán 1940-1944, obsérvese el trazado de la red de drenaje actual. En torno a las cabeceras de este sistema de drenaje natural destacan zonas inundables. Estas ofrecen resultados notables en la aplicación del Modelo 1. La aplicación del Modelo 2 conserva los resultados del primero, pero añade un peso mayor a los yacimientos que se encuentran aguas abajo, en relación con los cauces de los arroyos. Esta zona central gana además en visibilidad debido al mayor tamaño de los polígonos Thiessen asociados a los yacimientos, lo que implica una mayor disponibilidad de la no-riparia.

Los resultados sobre la ratio riparia-uinea se pueden contrastar con otros estudios SIG orientados por los principios agronómicos latinos sobre la cartografía y los modelos digitales del terreno actual. Este tipo de análisis fue realizado por $\mathrm{H}$. Goodchild para el valle del Tíber, extrayéndose estimaciones sobre producción, ocupación y demografía. En la misma línea metodológica, P. Trapero ha realizado un estudio sobre las posibilidades para la viticultura romana en un amplio sector del bajo valle del Guadalquivir. Este marco tiene la colonia de Hasta Regia como enclave central y engloba el área de estudio del presente trabajo (Goodchild 2013; Trapero 2016).

De los mapas resultantes se puede extraer una serie de apreciaciones. En primer lugar, los terrenos del área de la modelización riparia-uinea se encuentran orientados en una considerable proporción hacia el Norte, Noroeste y Oeste. El hecho resulta positivo para la viticultura por oponerse a la incidencia de los vientos del Sur y Sureste. De hecho, Columela especificó la conveniencia de esta orientación para las regiones cálidas, con el ejemplo de las costas béticas (Col. 3.12.6). Su tío Marco Columela, presumiblemente en el entorno gaditano, protegía las vides del viento de levante con esteras de palma (Col. 5.5.15). Esta condición es menos favorable en los extremos noroccidental y suroriental del 
área aquí modelizada. La zona de estudio en su totalidad es fundamentalmente plana, con escasa presencia de pendientes moderadas, y la insolación se mantiene en un grado medio. Existen distintos tipos de suelos, predominando los vertisoles en la parte central del área de estudio. Varias referencias de Columela a la actividad de su tío Marco en la Baetica aluden a la viticultura sobre distintos tipos de suelo. Este agricultor mezclaba tierras arenosas y arcillosas, consiguiendo mayor producción de cereales y viñas (Col. 2.15.4; Trapero 2016: 56). El transporte de tierras debió ser costoso e invita a situar esta actividad en zonas como la estudiada, con diversos tipos de suelos cercanos entre sí.

Las viñas cenagosas (palustres uineae) de Marco Columela (Col. 12.21.4) se han asociado a los vertisoles. Este tipo de tierra de cultivo es gris oscuro, granular y limo-arcillosa en la campiña andaluza. La capa arable de $40 \mathrm{~cm}$ es pesada, difícil de trabajar, de permeabilidad baja y mal drenaje. En las proximidades de Sanlúcar, Chipiona y Rota, los vertisoles eútricos son de textura más arenosa y estructura grumosa. Son más pesados y compactos en profundidad, dificultando la permeabilidad y el drenaje del subsuelo (Junta de Andalucía 1999). Estas palustres uineae de Marco Columela producían un vino que se podía mejorar mediante una elaborada técnica que incluía la incorporación de arrope (defrutum) (Col. 12.21.1-3). Esto puede considerarse indicativo del interés económico en las producciones vitícolas del entorno, posiblemente rentabilizadas por su inserción en los mercados urbanos y ultramarinos. El estudio de P. Trapero concluye con una serie cálculos de proximidad realizados a partir del modelo digital del terreno. Estos cálculos atañen a los asentamientos antiguos, las vías de comunicación fluvio-marítimas, la Via Augusta y las aguas superficiales. Lo poco accidentado de la orografía para la zona del modelado riparial uinea permite en general una distribución lineal y regular de las relaciones de proximidad con los distintos elementos de interés.

La distribución de los alfares romanos (figlinae) en el área de estudio y sus alrededores (fig. 8) se emplea a continuación como elemento de análisis crítico. Ocho

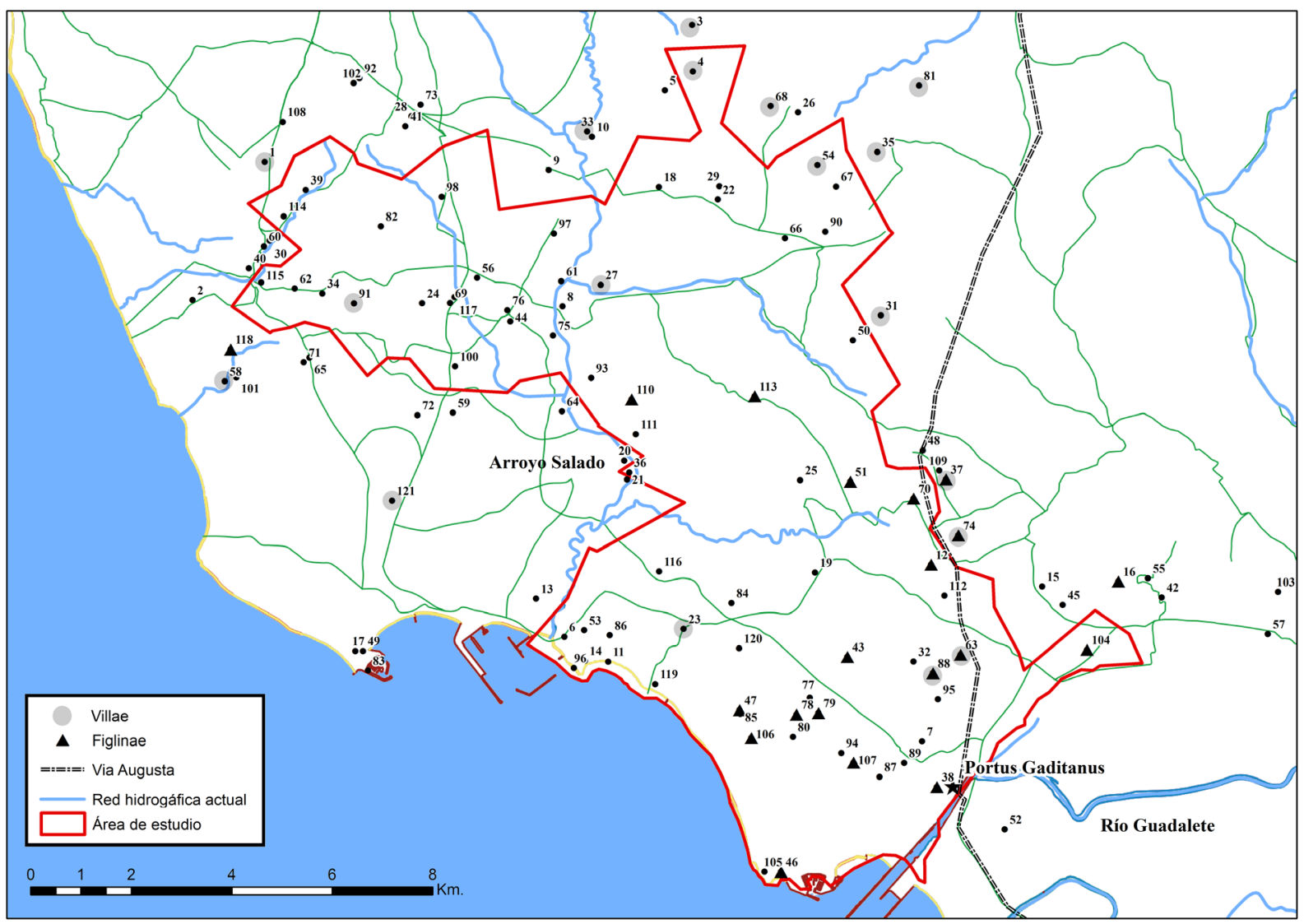

Figura 8. Distribución de villae y figlinae en relación con la Via Augusta, el Portus Gaditanus, la red hidrográfica y las vías pecuarias (en verde). 
figlinae se constatan en el área meridional de baja incidencia del modelado, añadiéndose una más en su periferia oriental. Tres figlinae pertenecen al área de escasa incidencia meridional. Cinco figlinae aparecen en el área de mayor incidencia septentrional, siendo tres las periféricas (dos orientales y una occidental). Una visión general de la distribución de las figlinae puede destacar la proximidad a las vías de comunicación terrestre. El caso de la Via Augusta se hace patente. Las figlinae más meridionales también parecen alinearse en torno a lo que habría de ser un camino. Ambas vías conducirían al Portus Gaditanus como punto de embarque de mercancías. Por otro lado, Venta Alta (núm. 113) y Vaína 1 (núm. 110), en El Puerto de Santa María, podrían enviar sus producciones a través del arroyo Salado. Esta vía acuática era navegable por embarcaciones de poco calado según noticias históricas recientes (López et al. 2008: 216), a lo que se añade la hipotética ubicación de un embarcadero romano en Campillo (núm. 20; Rota). En el extremo occidental y fuera del área de estudio, Viña las Cántaras (núm. 118; Rota) podría enviar sus producciones por la costa.

La distribución de las figlinae puede asociarse a la costa como vía de comunicación y al envasado de los derivados del pescado. Sin embargo, las figlinae que se encuentran tierra adentro, a varios kilómetros del Portus Gaditanus, pueden relacionarse en mayor medida con la producción anfórica destinada a los derivados de la uva. Figlinae como Venta Alta y Vaína 1 podrían haber producido para la exportación de sus propios excedentes, con mayor verosimilitud. Esto se explicaría por una mayor dificultad en las comunicaciones, el alejamiento relativo de los puntos de comercialización y la extensión de tierras asociables. Estas figlinae abastecerían a sus propietarios con el instrumentum domesticum necesario para una mayor autosuficiencia de la finca en la que se encontrarían.

Por último, se relaciona el área de estudio con los territoria de la colonia Hasta Regia y el municipium de Gades (fig. 9). Se añade la ubicación del Portus Gaditanus, reforzando la incidencia territorial del municipium, situado en la costa opuesta de la Bahía de Cádiz. Estrabón (Strab. 3.5.3) afirmaba que los gaditanos no ocupaban mucho de la costa situada enfrente. Esta noticia se ha puesto en relación con el hallazgo de un miliario en la Via Augusta, a la altura del yacimiento de La Florida (núm. 63; El Puerto de Santa María) (CIL II 4734; Sillières 1990: 114-115), que marcaría el límite territorial gaditano. Por tanto, la ubicación del Portus Gaditanus podría haber estado más relacionada con el comercio efectuado a través del río Guadalete que con el vínculo entre el municipium y su territorium o entorno inmediato.

Los tratados de agrimensura latinos permiten señalar algunas consideraciones relativas al confinium entre Hasta Regia y Gades. Este tipo de límite jurisdiccional aparecía descrito en los catastros romanos a partir de elementos naturales y antrópicos. Muchos de ellos se confundían con los propios de la delimitación u ocupación de las fincas (López 1994: 3-31; Castillo 1996: 5060). Entre estos últimos se incluyen los sepulchra y las fossae. Tales elementos se han hallado sobre el área de estudio (véase anexo 1), sin que su aparición sea definitoria desde la perspectiva territorial. Sin embargo, se puede recurrir a otro tipo de límites apuntados por los agrimensores. En primer lugar, la división por medio de un riuus señalaría el arroyo de Villarana como primera barrera notable entre el Portus Gaditanus y Hasta, enlazando con las elevaciones de la sierra de San Cristóbal (fig. 9). La diuergia aquarum o divisoria de aguas desplazaría esta frontera hacia el Sur. Por otro lado, las rutas ganaderas prehistóricas podrían haberse perpetuado hasta nuestros días en forma de vías pecuarias (Fairén et al. 2006: 55-57). En tanto que uiae romanas (Alfaro 2001: 216-219), habrían sido identificadores claros de los confinia. En el área de estudio, la Cañada del Verdugo enlazaría la desembocadura del arroyo Salado con las estribaciones de la sierra de San Cristóbal, cruzando la Via Augusta en las proximidades de La Florida (núm. 63). Combinado con la línea de la diuergia aquarum, este cruce y el miliario darían una referencia alternativa para el trazado de los confinia. También la vereda del Vado de Villarana o Camino de Rota se podría relacionar con las vertientes de aguas, separando la cuenca baja del Salado. Asimismo, esta vía separa las concentraciones de yacimientos situados en el extremo meridional del área modelizada (fig. 2 y 9).

Por último, una serie de anillos concéntricos cada 5 kilómetros (fig. 10) expone la relación de distancias lineales. El área de estudio quedaría englobada en un radio de 20 kilómetros en torno a Gades y su portus. En el caso de Hasta Regia, un radio similar solo dejaría fuera el extremo meridional del área de estudio. El Portus Gaditanus aparece como opción más favorable en relación a estas distancias lineales.

Un análisis crítico desde el punto de vista históricogeográfico matiza la anterior visión espacial. En primer lugar, las comunicaciones fluvio-marítimas facilitarían la conexión con Gades. La Via Augusta conectaba Portus Gaditanus con Hasta Regia y sería el eje de comunicación terrestre prioritario en la región. El transporte de mercancías se vería enfocado hacia la bahía de Cádiz 


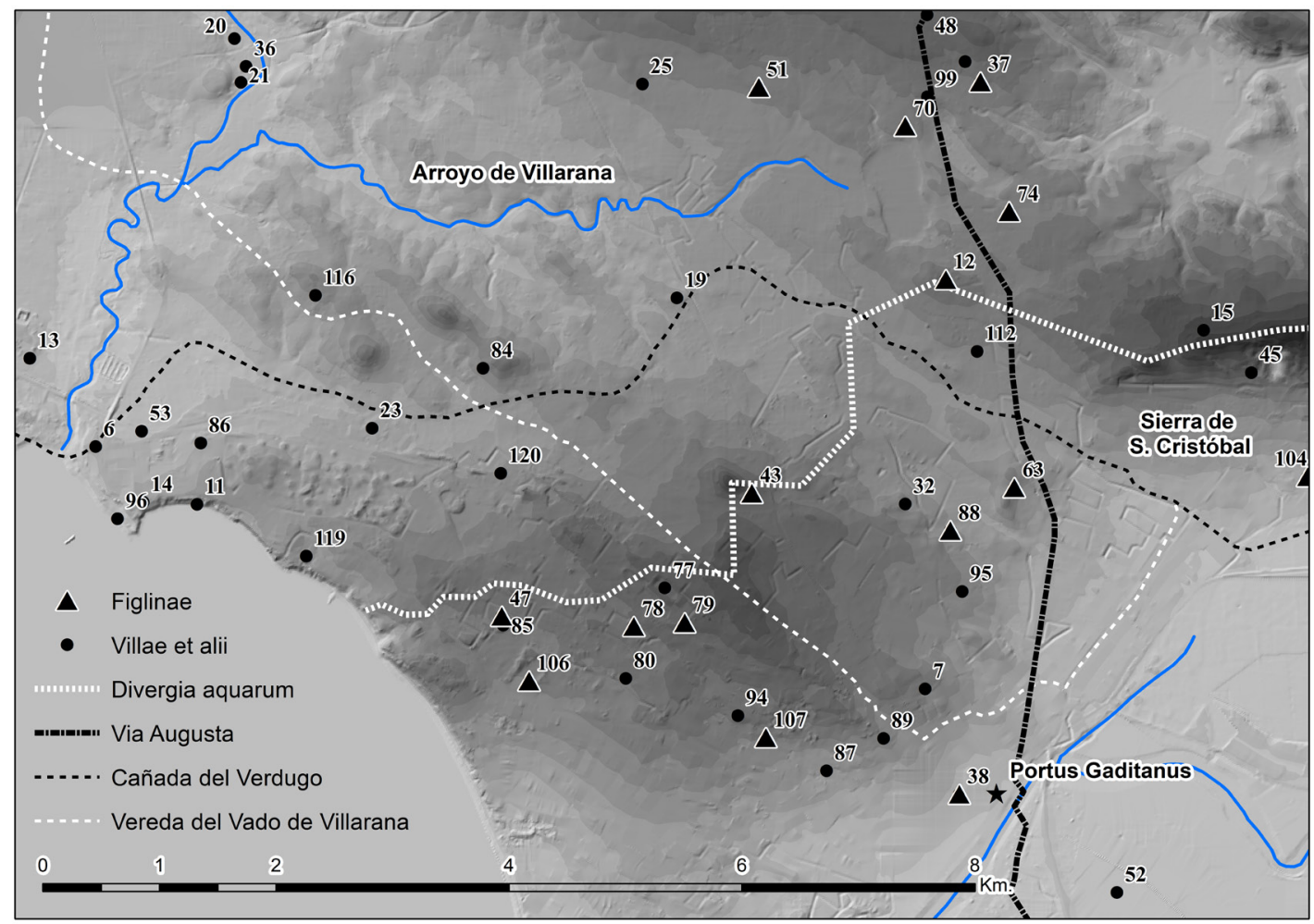

Figura 9. Elementos para la ubicación del confinium entre la colonia Hasta Regia y el municipium de Gades.

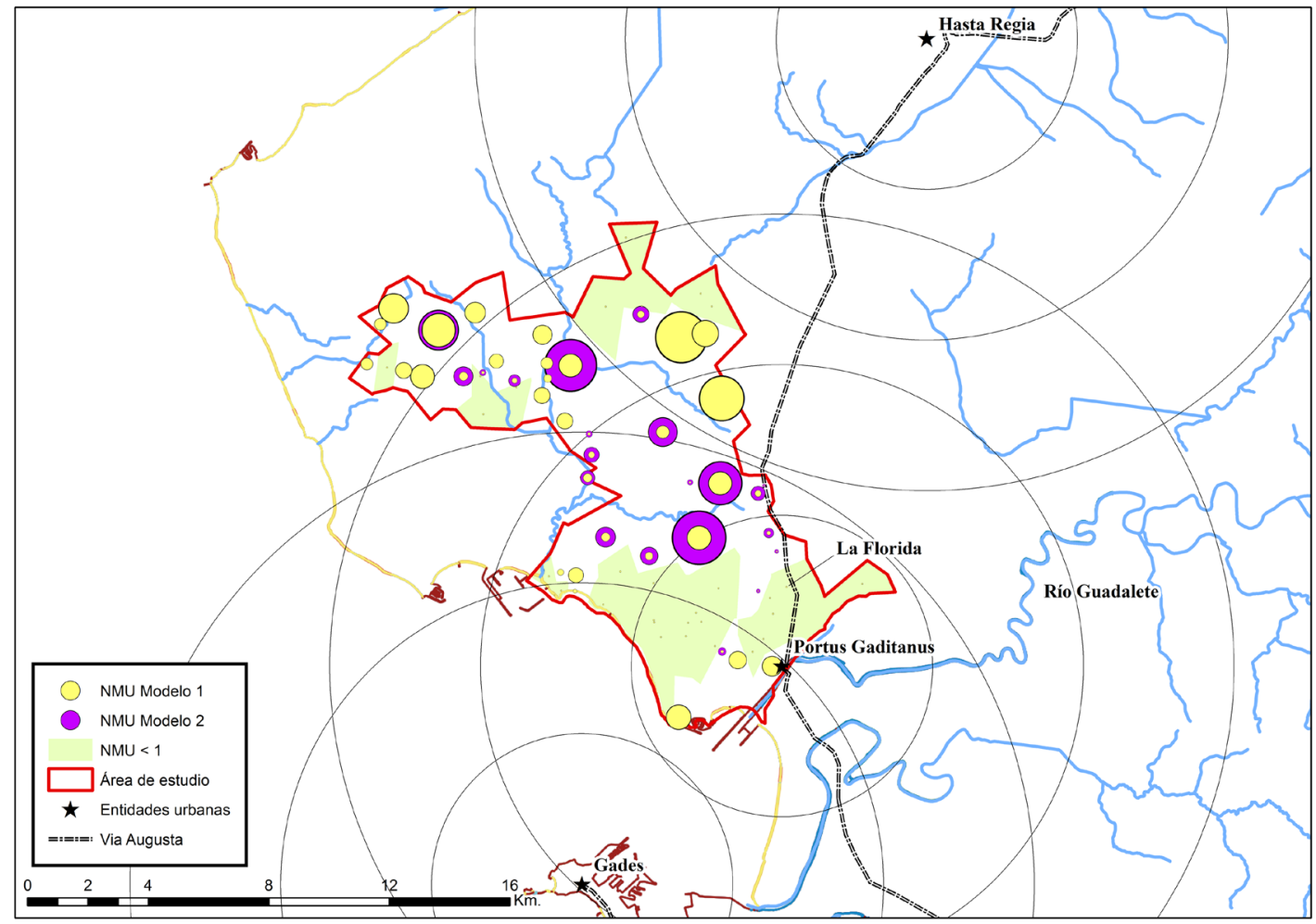

Figura 10. Distancias lineales entre los enclaves urbanos y el área de modelado de la ratio riparia/uinea.

ISSN: $1133-4525 \quad$ ISSN-e: $2255-3924$ 
pero la comunicación terrestre sería buena con Hasta Regia. De tal forma, los hastenses podrían haber tenido posesiones en buena parte de la zona de estudio, aunque estrechamente conectadas con el ámbito gaditano.

\section{CONCLUSIONES}

Aquella ciudad que se apropiara con anterioridad del área más apta para la implantación de la ratio riparia/ uinea pudo cultivar más fácilmente un viñedo emparrado. Este tipo de cultivo ofrece ventajas para la vinificación, tal y como indicaba Columela (Col. Arb. 4.1-2), y por tanto podría haber supuesto un mayor rendimiento económico.

La población gaditana asentada en la costa continental habría tenido una mayor relación con el comercio (Strab. 3.2.2 y 3.5.3) y los recursos pesqueros. Su influencia en el territorio se habría limitado a una zona donde la aplicabilidad de la ratio riparia/uinea habría sido escasa o nula. Las necesidades de autoabastecimiento y la comercialización de los excedentes junto con otros productos como las salazones de pescado habrían favorecido la viticultura. El viñedo habría sido adaptado a la poda en vaso en ámbitos como este. Esta práctica corresponde a lo esperado en contextos de tradición púnica (Col. Arb. 4.1-2) como el territorium del municipium de Gades. Las grandes cantidades de mosto así obtenidas, mayores que la del viñedo emparrado, pudieron dedicarse a la fabricación de conservas como la sapa o el defrutum.

La población hastense pudo verse abocada desde un principio a una dedicación agraria. La ciudad parece haber sido una importante potencia territorial desde tiempos prerromanos, con influencia al sur del río Guadalete, según indicaría el conocido bronce de la Torre Lascutana (CIL II 5041). Por tanto, no sería extraño que la ciudad se hubiese apropiado del área de implantación preferente de los modelos. Además, la presencia de ciudadanos romanos enriquecidos ya en época de la guerra civil cesariana (B. Hisp. 26.2) incidiría en la posibilidad de una temprana implantación de modelos agrícolas itálicos. En este momento se podría haber aplicado la técnica del emparrado para obtener vinos que cubrieran las necesidades y expectativas de los nuevos pobladores. De hecho, el potencial especulativo del vino podría justificar la aplicación de este sistema de conducción, que resultaba más caro. La zona central del área de estudio podría haber recibido una atención preferente en este sentido, puesto que contaba con los medios naturales apropiados. La producción excedentaria de vino también podría haber cubierto una carencia propia del ámbito gaditano y haber aprovechado igualmente el potencial comercial de la ciudad vecina. Estrabón (Strab. 3.2.2) indicó que los gaditanos solían acudir a Hasta Regia. Este hecho sugiere que se abastecían de sus productos en mercados periódicos. La interpretación del área de estudio podría proponer un acercamiento inverso, es decir, de los productores hastenses a los consumidores gaditanos. No hay que olvidar, sin embargo, el fenómeno del incolatus. Los potentados gaditanos podrían haberse establecido en estas tierras hastenses para explotarlas, incluso adoptando un método itálico. Contrariamente, los hastenses también podrían haber ocupado este espacio como incolae, en el caso de que hubiera pertenecido al territorium de Gades.

En cualquier caso, parte de los terrenos aptos para una mayor aplicación de los modelos empleados coincide con un área de baja densidad de asentamientos rurales romanos. Esto asocia grandes superficies a dichos enclaves, sugiriendo un espacio preferente para el establecimiento de la gran explotación. Otras parcelas de menor tamaño se darían en espacios donde la aplicación del modelado ofrece resultados negativos. Sin embargo, en la zona noroeste del área de estudio se observa una mayor densidad de asentamientos, con menores parcelas asociadas. Este patrón podría responder a la notable presencia de espacios inundables. Estos pudieron aprovecharse sin necesidad de ser completamente transformados, por ejemplo mediante la creación de prados. No obstante, la densidad de la ocupación rural parece responder más bien a una explotación intensiva. Así pues, esta zona inicialmente marginal podría haber sido ocupada por pequeños propietarios que lograran cultivarla por completo gracias al drenaje. Una gestión adaptada de las zonas inundables podría haber deparado una mayor aplicabilidad de la ratio riparia/uinea en fincas autosuficientes. Es decir, se podrían haber aumentado las tierras de cultivo y creado espacios ribereños en torno a las estructuras de drenaje. De tal forma se habrían aumentado los recursos para extender aún más la viticultura cum pedamentis.

En síntesis, el modelado de la ratio riparia/uinea parte de unas líneas generales del pensamiento agronómico latino. Su objetivo es explorar la aplicabilidad de un precepto específico a un determinado espacio geográfico. El modelado está sujeto a múltiples parámetros cuya variación podría conducir a conclusiones diversas. Los resultados quedan pendientes de confrontación con nuevas evidencias, tanto para el área de estudio seleccionada como para otras zonas donde se cumplieran 
los parámetros histórico-geográficos establecidos. Así pues, los patrones de asentamiento dependerían de los sistemas de explotación agrícola y viceversa. Estas complejas construcciones culturales pudieron verse afectadas por factores simples, como la posibilidad de implantar una viticultura cum pedamentis. La modelización aquí empleada establece un marco epistemológico y un contexto hipotético para sopesar tal impacto. $\mathrm{Su}$ análisis crítico ha permitido apreciar cierta verosimilitud de los resultados y valorar su posible adecuación a un contexto colonial romano.

\section{Agradecimientos}

Este trabajo se ha desarrollado en el seno del EPNet Project Production and Distribution of Food during the Roman Empire: Economic and Political Dynamics (ERC-2013-ADG 340828); European Research Council; I.P. José Remesal Rodríguez. El grupo CEIPAC (Centro para el Estudio de la Interdependencia Provincial en la Antigüedad Clásica), al que pertenecen ambos autores, también es beneficiario del proyecto HAR2015-66771-P (MINECO/FEDER, UE).

\section{ANEXO 1}

\begin{tabular}{|c|c|c|c|c|c|}
\hline & Denominación & Bibliografía & Identificación & Inicio & Final \\
\hline 1 & Alcanfora & Sánchez 2010: 93-96 y 174-176 & uilla & & \\
\hline 2 & Alfar de la Peña & Sánchez 2010: 119, 121, 128 y 174-176 & & & \\
\hline 3 & Alijar (Cortijo de) & Ponsich 1991: 197 y 216 & localización; uilla & & 500 d.C. \\
\hline 4 & Alijarillo & Ponsich 1991: 197 y 216 & $\begin{array}{l}\text { uilla; asentamiento } \\
\text { rural }\end{array}$ & & \\
\hline 5 & Alijarillo (Oeste) & Ponsich 1991: 197 y 216 & asentamiento rural & & \\
\hline 6 & Almenas, Las & Sánchez 2010: 119, 123, 129 y 174-176 & & & \\
\hline 7 & Angelita, La & López y Pérez 2013: 167 & & & \\
\hline 8 & Arenas de Campín & Sánchez 2010: 118 y 174-176 & & & \\
\hline 9 & $\begin{array}{l}\text { Atalaya (Cortijo de) } \\
\text { (Oeste) }\end{array}$ & Ponsich 1991: 197 y 217 & localización & & \\
\hline 10 & Atalaya, La & López y Pérez 2013: 167 y 184 & & & \\
\hline 11 & Barranca de Huete & Sánchez 2010: 119, 128 y 174-176 & necrópolis & & \\
\hline 12 & Barranco & $\begin{array}{l}\text { Lagóstena y Bernal 2004: 61; López y Pérez, } \\
\text { 2013: } 167 \text { y 173; }\end{array}$ & $\begin{array}{l}\text { asentamiento rural; } \\
\text { figlina }\end{array}$ & 14 d.C. & 711 d.C. \\
\hline 13 & Base de Rota & Sánchez 2010: 120, 122-123 y 174-176 & silos & & \\
\hline 14 & Base Naval & Sánchez 2010: 119, 129 y 174-176 & necrópolis & & \\
\hline 15 & Beatillas, Las & SIPHA & asentamiento rural & & \\
\hline 16 & Buenavista & $\begin{array}{l}\text { Lagóstena y Bernal 2004: 62; López y Pérez, } \\
\text { 2013: } 167\end{array}$ & $\begin{array}{l}\text { asentamiento rural; } \\
\text { figlina }\end{array}$ & 150 a.C. & 54 d.C. \\
\hline 17 & Calle Charco 6 & Sánchez 2010: 133-134 y 174-176 & necrópolis & & \\
\hline 18 & Camino de Regla & López y Pérez 2013: 167 & & & \\
\hline 19 & Camino Villarana & López y Pérez 2013: 167 & & & \\
\hline 20 & Campillo & Sánchez 2010: 104-105 y 174-176 & embarcadero & & \\
\hline 21 & Campillo Alto & Sánchez 2010: 104-106 y 174-176 & & & \\
\hline 22 & Campín Alto & López y Pérez 2013: 167 & & & \\
\hline
\end{tabular}




\begin{tabular}{|c|c|c|c|c|c|}
\hline & Denominación & Bibliografía & Identificación & Inicio & Final \\
\hline 23 & Campsa & López y Pérez 2013: 167 y 180 & uilla & & \\
\hline 24 & Capitana 2 & Sánchez 2010: 107, 130 y 174-176 & & & \\
\hline 25 & Casa Rocío & López y Pérez 2013: 167 y 184 & & & 500 d.C. \\
\hline 26 & Casa Alta (Norte) & Ponsich 1991: 197 y 215 & asentamiento rural & & \\
\hline 27 & Casa Blanca & Ponsich 1991: 197 y 217 & uilla & & \\
\hline 28 & $\begin{array}{l}\text { Casa Buena o Casa } \\
\text { Nueva }\end{array}$ & Sánchez 2010: 108-109 y 174-176 & & & \\
\hline 29 & Casa de Champín & Ponsich 1991: 197 y 217 & localización & & \\
\hline 30 & Casa de la Palma & Sánchez 2010: 94-95 y 174-176 & & & \\
\hline 31 & Casa de la Pintada & López y Pérez 2013: 167 y 173-174 & uilla & & \\
\hline 32 & Casa de las Monedas & López y Pérez 2013: 167 & & & \\
\hline 33 & $\begin{array}{l}\text { Casa de San José } \\
\text { (Sur) }\end{array}$ & Ponsich 1991: 197 y 217 & uilla & & 500 d.C. \\
\hline 34 & Casa de Toraño & Sánchez 2010: 99-100 y 174-176 & & & \\
\hline 35 & Casa El Cuadrado & Ponsich 1991: 197 y 215 & uilla & & 500 d.C. \\
\hline 36 & Casa Machaca & Sánchez 2010: 106-107 y 174-176 & & & \\
\hline 37 & Casa Vicuña & $\begin{array}{l}\text { Lagóstena y Bernal 2004: 62; López y Pérez } \\
\text { 2013: 167, } 172 \text { y } 174\end{array}$ & uilla; figlina & 25 a.C. & 200 d.C. \\
\hline 38 & Casco Urbano & López y Pérez 2013: 167 & & & \\
\hline 39 & Cebollares & Sánchez 2010: 95, 105 y 174-176 & & & \\
\hline 40 & Cebollares Rincones & Sánchez 2010: 116, 118, 120 y 174-176 & & & \\
\hline 41 & $\begin{array}{l}\text { Cerro de Juan Cas- } \\
\text { tilla }\end{array}$ & Sánchez 2010: 109, 113 y 174-176 & & & \\
\hline 42 & Cerro de la Cueva & SIPHA & asentamiento rural & & \\
\hline 43 & Cerro de las Cabezas & Lagóstena y Bernal 2004: 63 & $\begin{array}{l}\text { figlina; estructura } \\
\text { hidráulica }\end{array}$ & 50 & 125 d.C. \\
\hline 44 & $\begin{array}{l}\text { Cerro de las Cabezas } \\
\text { hornillos }\end{array}$ & Sánchez 2010: 110-111 y 174-176 & & & \\
\hline 45 & Cerro Verde & López y Pérez 2013: 167 & & & \\
\hline 46 & China, La & $\begin{array}{l}\text { Lagóstena y Bernal 2004: 63; López y Pérez, } \\
\text { 2013: } 167\end{array}$ & figlina & 25 a.C. & 50 d.C. \\
\hline 47 & Cipreses, Los & $\begin{array}{l}\text { Lagóstena y Bernal 2004: 62; López y Pérez, } \\
\text { 2013: } 167\end{array}$ & $\begin{array}{l}\text { asentamiento rural; } \\
\text { figlina }\end{array}$ & 25 a.C. & 150 d.C. \\
\hline 48 & Conejo, El & López y Pérez 2013: 167, 172 y 174 & & 100 a.C. & 200 d.C. \\
\hline 49 & Convento La Merced & Sánchez 2010: 134-136 y 174-176 & & & \\
\hline 50 & Cortijo de la Roa & SIPHA & asentamiento rural & & \\
\hline 51 & Cortijo de Permita & SIPHA & & & \\
\hline
\end{tabular}




\begin{tabular}{|c|c|c|c|c|c|}
\hline & Denominación & Bibliografía & Identificación & Inicio & Final \\
\hline 52 & Coto la Isleta & López y Pérez 2013: 167 & & & \\
\hline 53 & Cruce de las Almenas & Sánchez 2010: 123, 130 y 174-176 & & & \\
\hline 54 & Cuco (El) & Ponsich 1991: 197 y 215 & uilla & & \\
\hline 55 & Cueva El Civil & López y Pérez 2013: 167 & & & \\
\hline 56 & Dehesa Nueva & Sánchez 2010: 114, 116 y 174-176 & & & \\
\hline 57 & Doña Blanca & López y Pérez 2013: 167 & & & \\
\hline 58 & Elice & Sánchez 2010: 89, 127 y 174-176 & uilla & & \\
\hline 59 & Espillaga & Sánchez 2010: 113-114, 125 y 174-176 & necrópolis & & \\
\hline 60 & Estamborera, La & Sánchez 2010: 94-95 y 174-176 & & & \\
\hline 61 & Estupillana & Sánchez 2010: 114, 125 y 174-176 & & & \\
\hline 62 & Farolera & Sánchez 2010: 100-102 y 174-176 & & & \\
\hline 63 & Florida, La & $\begin{array}{l}\text { Lagóstena y Bernal 2004: 63; López y Pérez } \\
\text { 2013: 167-171 }\end{array}$ & $\begin{array}{l}\text { uilla; cisterna; fossa; } \\
\text { figlina }\end{array}$ & 125 a.C. & 100 d.C. \\
\hline 64 & Fontanar & Sánchez 2010: 114, 127 y 174-176 & & & \\
\hline 65 & Fuente del Loro & Sánchez 2010: 101-102 y 174-176 & & & \\
\hline 66 & $\begin{array}{l}\text { Gallo (El) (Cortijo } \\
\text { de) }\end{array}$ & Ponsich 1991: 197 y 218 & localización & & \\
\hline 67 & Grañina & López y Pérez 2013: 167 & & & \\
\hline 68 & Herrador (Cortijo de) & Ponsich 1991: 197 y 215 & uilla & & 500 d.C. \\
\hline 69 & Jardal (El Pardal) & Sánchez2010: 114, 116-117, 127 y 174-176 & & & \\
\hline 70 & Laguna Salada & $\begin{array}{l}\text { Lagóstena y Bernal 2004: 64; López y Pérez } \\
\text { 2013: } 167 \text { y 171-172 }\end{array}$ & & 25 a.C. & 50 d.C. \\
\hline 71 & Lince, El & Sánchez 2010: 101, 103 y 174-176 & & & \\
\hline 72 & Llagunetas & Sánchez 2010: 113, 125 y 174-176 & & & \\
\hline 73 & Lomo de Casa Nueva & Sánchez 2010: 108-109 y 174-176 & & & \\
\hline 74 & Manoteras & $\begin{array}{l}\text { Lagóstena y Bernal 2004: 64; López y Pérez } \\
\text { 2013: 167, } 171 \text { y } 174\end{array}$ & uilla & 100 a.C. & 200 d.C. \\
\hline 75 & Meloneras & Sánchez 2010: 112, 115 y 174-176 & & & \\
\hline 76 & Mezquita & Sánchez 2010: 111-113 y 174-176 & & & \\
\hline 77 & Molino Platero 1 & López y Pérez 2013: 167 & & & \\
\hline 78 & Molino Platero 2 & $\begin{array}{l}\text { Lagóstena y Bernal 2004: 64; López y Pérez } \\
\text { 2013: } 167\end{array}$ & figlina & 1 d.C. & 200 d.C. \\
\hline 79 & Molino Platero 3 & $\begin{array}{l}\text { Lagóstena y Bernal 2004: 64; López y Pérez } \\
\text { 2013: } 167\end{array}$ & figlina & 1 d.C. & 200 d.C. \\
\hline 80 & Molino Platero 4 & López y Pérez 2013: 167 & & & \\
\hline 81 & Montaña (Cortijo de) & Ponsich 1991: 197 y 215 & uilla & & 500 d.C. \\
\hline
\end{tabular}




\begin{tabular}{|c|c|c|c|c|c|}
\hline & Denominación & Bibliografía & Identificación & Inicio & Final \\
\hline 82 & Monte Petri & Sánchez 2010: 108-110 y 174-176 & & & \\
\hline 83 & Muelle Viejo & Sánchez 2010: 143-144 y 174-176 & portus & & \\
\hline 84 & Negra, La & López y Pérez 2013: 167 & & & \\
\hline 85 & Pago de Cantarranas & SIPHA; Lagóstena 1994 & área de ocupación & & \\
\hline 86 & Pago de la Mata & Sánchez 2010: 119, 123, 129 y 174-176 & necrópolis & & \\
\hline 87 & Palmas, Las & López y Pérez 2013: 167 & & & \\
\hline 88 & Palomar, El & $\begin{array}{l}\text { Lagóstena y Bernal 2004: 64; López y Pérez, } \\
\text { 2013: 165-170 }\end{array}$ & $\begin{array}{l}\text { uilla; asentamiento } \\
\text { rural; figlina }\end{array}$ & 100 a.C. & 200 d.C. \\
\hline 89 & Pinar, El & López y Pérez 2013: 167 & & & \\
\hline 90 & Pocito Chico & López y Pérez 2013: 167 y 183-184 & & 100 a.C. & \\
\hline 91 & Poedo, El (1) & Sánchez 2010: 94, 97 y 174-176 & uilla & & \\
\hline 92 & Poedo, El (2) & Sánchez 2010: 94, 97 y 174-176 & & & \\
\hline 93 & Prado de los Potros & Sánchez 2010: 112, 115 y 174-176 & & & \\
\hline 94 & Puerto 12 & SIPHA & factoría de salazones & & \\
\hline 95 & Puerto Nuevo & López y Pérez 2013: 167 & & & \\
\hline 96 & $\begin{array}{l}\text { Puntilla de Fuente- } \\
\text { bravía }\end{array}$ & Sánchez 2010: 119, 122, 124 y 174-176 & necrópolis & & \\
\hline 97 & Queso, El & Sánchez 2010: 118 y 174-176 & & & \\
\hline 98 & Ranchillo & Sánchez 2010: 110-111 y 174-176 & & & \\
\hline 99 & Rancho Biruela & Sillieres 1977 & & & \\
\hline 100 & Regodón & Sánchez 2010: 106-108 y 174-176 & necrópolis & & \\
\hline 101 & Río Martín & Sánchez 2010: 91-93 y 174-176 & & & \\
\hline 102 & Salud, La & Sánchez 2010: 94, 97 y 174-176 & necrópolis & & \\
\hline 103 & San Cristóbal & López y Pérez 2013: 167 & & & \\
\hline 104 & San Ignacio & $\begin{array}{l}\text { Lagóstena y Bernal 2004: 66; López y Pérez, } \\
\text { 2013: } 167\end{array}$ & figlina & 25 a.C. & 100 d.C. \\
\hline 105 & Santa Catalina & López y Pérez 2013: 167 & & & \\
\hline 106 & Sauces, Los & $\begin{array}{l}\text { Lagóstena y Bernal 2004: 66; López y Pérez, } \\
\text { 2013: } 167\end{array}$ & figlina & 50 a.C. & 25 d.C. \\
\hline 107 & Tío Prieto & $\begin{array}{l}\text { Lagóstena y Bernal 2004: 63; López y Pérez, } \\
\text { 2013: } 167\end{array}$ & figlina & 25 a.C. & 25 d.C. \\
\hline 108 & Torre Breva & Sánchez 2010: 97, 99 y 174-176 & & & \\
\hline 109 & Totín & SIPHA & asentamiento rural & & \\
\hline 110 & Vaina (1) & $\begin{array}{l}\text { Lagóstena y Bernal 2004: 66; López y Pérez } \\
\text { 2013: } 167 \text { y } 184\end{array}$ & $\begin{array}{l}\text { asentamiento rural; } \\
\text { figlina }\end{array}$ & 200 a.C. & 500 d.C. \\
\hline 111 & Vaina (2) & López y Pérez 2013: 167 y 184 & & & 500 d.C. \\
\hline
\end{tabular}




\begin{tabular}{|c|c|c|c|c|c|}
\hline & Denominación & Bibliografía & Identificación & Inicio & Final \\
\hline 112 & Vaquerias & López y Pérez 2013: 167 & & & \\
\hline 113 & Venta Alta & $\begin{array}{l}\text { Lagóstena y Bernal 2004: 66; López y Pérez } \\
\text { 2013: } 167\end{array}$ & $\begin{array}{l}\text { asentamiento rural; } \\
\text { figlina }\end{array}$ & 200 a.C. & 500 d.C. \\
\hline 114 & Vicaría, La & Sánchez 2010: 96-98 y 174-176 & & & \\
\hline 115 & Villar, El & Sánchez 2010: 103-105, 116 y 174-176 & & & \\
\hline 116 & Villarana & López y Pérez 2013: 167 & & & \\
\hline 117 & Villarejo & Sánchez 2010: 116, 120, 127 y 174-176 & & & \\
\hline 118 & Viña las Cántaras & $\begin{array}{l}\text { Lagóstena y Bernal 2004: 74; Sánchez 2010: } 93 \\
\text { y 174-176 }\end{array}$ & & 1 d.C.. & 300 d.C \\
\hline 119 & Viña, La & López y Pérez 2013: 167 y 178-180 & necrópolis; fossa & & \\
\hline 120 & Viveros & López y Pérez 2013: 167 & & & \\
\hline 121 & Yacimiento A & McClellan et al. 2010: 109 & uilla & 40 a.C. & 600 d.C. \\
\hline
\end{tabular}

\section{BIBLIOGRAFÍA}

Alfaro Giner, C. (2001): "Vías pecuarias y romanización en la Península Ibérica”, en J. Gómez-Pantoja (ed.), Los rebaños de Gerión. Pastores y trashumancia en Iberia antigua y medieval: 215-231. Madrid, Casa de Velázquez. https://books.openedition. org/cvz/2693?lang=es

André, J. (1985): Les noms de plantes dans la Rome Antique. Paris, Les Belles Lettres.

Blázquez Martínez, J.M. (1996): "Técnicas agrícolas representadas en los mosaicos del Norte de África", en L'Africa Romana XI. Atti dell'XI convegno di studio. Cartagine, 15-18 dicembre 1994: 517-527. Sassari. http://www.cervantesvirtual.com/obra/tcnicas-agrcolas-representadas-en-los-mosaicos-delnorte-de-frica-0/

Castillo Pascual, M.J. (1996): Espacio en orden. El modelo gromático de ordenación del territorio. Logroño, Universidad de La Rioja. https://dialnet.unirioja.es/servlet/libro? codigo $=230779$

Chouquer, G. y Favory, F. (2001): L'arpentage romain. Histoire des textes - Droit - Techniques. Paris, Editions Errance.

Cubero Salmerón, J.I. (traducción y comentarios de) (2010): Rerum Rusticarum Libri III. Marco Terencio Varrón. Sevilla, Junta de Andalucía. https:// www.ucm.es/data/cont/media/www/pag-79266/ ResRustica.pdf

Duncan-Jones, R. (1974): The Economy of the Roman empire: quantitative studies. London, Cambridge University Press.
Fairén Jiménez, S.; Cruz Berrocal, M.; López-Romero González de la Aleja, E. y Walid Sbeinati, S. (2006): "Las vías pecuarias como elementos arqueológicos", en I. Grau Mira (ed.), La aplicación de los SIG en la Arqueología del Paisaje: 55-68. San Vicente del Raspeig, Universidad de Alicante. https://www. academia.edu/3132517/Las_v\%C3\%ADas_pecuarias_como_elementos_arqueol\% $\mathrm{C} 3 \% \mathrm{~B} 3$ gicos

Figueiral, I.; Bouby, L.; Buffat, L.; Petitot, H. y Terral, J.-F. (2010): “Archaeobotany, vine growing and wine producing in Roman Southern France: the site of Gasquinoy (Béziers, Hérault)". Journal of Archaeological Science 37: 139-149. DOI: https://doi. org/10.1016/j.jas.2009.09.024

Figueiral, I. y Séjalon, P. (2014): “Archaeological wells in southern France: Late Neolithic to Roman plant remains from Mas de Vignoles IX (Gard) and their implications for the study of settlement, economy and environment". Environmental Archaeology 191: 23-38. DOI: https://doi.org/10.1179/17496314 13Y.0000000009

Garcia, J.-P. (2011): "Une vigne gallo-romaine de plaine à Gevrey-Chambertin (Côte-d'Or), Ier-IIe s. apr. J.-C.”. Gallia 68-1: 93-110. http://journals.openedition.org/rae/6289?file $=1$

García Armendáriz, J.I. (introducción, traducción y notas de) (2004): Columela. Libro de los árboles, La labranza. Madrid, Editorial Gredos.

García Sanjuán, L. (2005): Introducción al Reconocimiento y Análisis Arqueológico del Territorio. Barcelona, Ariel. https://dialnet.unirioja.es/servlet/ articulo? codigo $=3297276$. 
García-Gelabert Pérez, M.P. y García-Gelabert Rivero, E. (2009-2010): "Reflejo de la vendimia y aplicaciones derivadas en los textos clásicos, en los mosaicos de Hispania y África y en sarcófagos romanos". Hispania Antiqva XXXIII-XXXIV: 187-224. http://uvadoc.uva.es/bitstream/10324/9776/1/HispaniaAntiqua-2009.10-33.34-Reflejodelavendimia. pdf

Goodchild, H. (2013): "GIS Models of Roman Agricultural Production", en A. Bowman y A. Wilson (eds.), The Roman Agricultural Economy. Organization, Investment, and Production: 55-83. Oxford, Oxford University Press. DOI: http://dx.doi. org/10.1093/acprof:oso/9780199665723.003.0003

Hodder, I. y Orton, C. (1976): Análisis espacial en Arqueología. Barcelona, Editorial Crítica.

López Paz, P. (1994): La ciudad romana ideal. El territorio. Santiago de Compostela, Editorial de la Historia.

Junta de Andalucía (1999): Informe sobre los criterios y estándares para declarar un suelo contaminado en Andalucía y la metodología y técnicas de toma de muestra y análisis para su investigación. [En línea]. Sevilla, Junta de Andalucía (Informes técnicos) 1999. http://www.juntadeandalucia.es/medioambiente/web/Bloques_Tematicos/Estado_Y_Calidad De_Los_Recursos_Naturales/Suelo/Criterios pdf/Cadiz.pdf. [03 de junio de 2016]

Lagóstena Barrios, L. y Bernal Casasola, D. (2004): "Alfares y producciones cerámicas en la provincia de Cádiz. Balance y perspectivas", en D. Bernal y L. Lagóstena (eds.), Figlinae Baeticae. Talleres alfareros y producciones cerámicas en la Bética romana (ss. II a.C.-VII d.C.). Actas del Congreso Internacional: 39-124. Cádiz (2003), Oxford, BAR Publishing. http://www.exofficinahispana.org/Articulos\%20y\%20Comunicaciones/BO0161.pdf

López Amador, J.J. y Pérez Fernández, E. (2013): El puerto gaditano de Balbo. El Puerto de Santa María. Cádiz. El Puerto de Santa María, Ediciones El Boletín. http://www.traianvs.net/pdfs/2013_portus_ gaditanus.pdf

López Amador, J.J.; Ruiz Mata, D. y Ruiz Gil, J.A. (2008): "El entorno de la Bahía de Cádiz a fines de la Edad del Bronce e inicios de la Edad del Hierro". RAMPAS, Revista Atlántica-Mediterránea de Prehistoria y Arqueología Social 10: 215-236. DOI: http://dx.doi.org/10.25267/Rev_atl-mediterr_prehist_arqueol_soc.2008.v10.06

McClellan, M.C.; Reinoso del Río, M.C.; Gutiérrez López, J.M. y Mackinnon, M. (2010): “Una villa romana en la Base Naval", en J.M. Gutiérrez López (ed. científico), De la Prehistoria a la Rábita y la Villa. Arqueología de Rota y la Bahía de Cádiz: 109-147. Chiclana de la Frontera, Fundación Alcalde Zoilo Ruiz-Mateos.

Martin, R. (1971): Recherches sur les agronomes latins et leurs conceptions économiques et sociales. Paris, Les Belles Lettres.

Martín Gutiérrez, E. (2004): La organización del paisaje rural durante la Baja Edad Media. El ejemplo de Jerez de la Frontera. Sevilla, Universidad de Cádiz, Universidad de Sevilla.

Martín Oliveras, A. (2015): Arqueologia del vi a l'època romana. Del cultiu al consum. Marc teòric $i$ epistemolòic. Barcelona, Societat Catalana d'Arqueologia.

Martín Oliveras, A.; Martín-Arroyo Sánchez, D.J. y Revilla Calvo, V. (2017): "Wine economy in Roman Spain: archaeological data and modelization", en J. Remesal Rodríguez (ed.), Economía romana. Nuevas perspectivas. The Roman Economy. New perspectives: 189-237. Barcelona, Universitat de Barcelona. http://ceipac.ub.edu/biblio/Data/A/0940.pdf

Martín-Arroyo Sánchez, D.J. (2010): “Drenaje de espacios agropecuarios romanos: concepción e identificación", en L. Lagóstena, L. Cañizar y L. Pons (eds.), Aquam·Perducendam.Curavit. Captación, uso y administración del agua en las ciudades de la Bética y el Occidente romano: 397-408. Cádiz, Universidad de Cádiz. http://ceipac.ub.edu/biblio/ Data/A/0733.pdf

Martín-Arroyo Sánchez, D.J. (2016): "Modelización de la ratio riparia/uinea: el emparrado romano entre Hasta Regia y Gades", en L. Lagóstena (ed.), Lacus autem idem et stagnus, ubi inmensa aqua convenit (Isid. Etym. 13.19.9). Estudios históricos sobre humedales en la Bética (II): 105-124. Cádiz, Seminario Agustín de Horozco de Estudios Económicos de Historia Antigua y Medieval. http://ceipac.ub.edu/ biblio/Data/A/0845.pdf

Martín-Arroyo Sánchez, D.J. y Castro García, M. del M. (en prensa): "GIS-based Modelling for the $R i$ paria/Vinea Ratio: from Portus Gaditanus to $\mathrm{Na}$ brissa Veneria", en The production and distribution of food in the Roman Empire: modelling political, economic and social dynamics. Barcelona, Universitat de Barcelona.

Martín-Arroyo Sánchez, D.J. y Trapero Fernández, P. (2015): "La explotación romana de la vegetación riparia y el análisis espacial de la ocupación rural", en L. Lagóstena (ed.), Qui lacus aquae stagna 
paludes sunt... Estudios históricos sobre humedales en la Bética: 243-260. Cádiz, Seminario Agustín de Horozco de Estudios Económicos de Historia Antigua y Medieval. http://ceipac.ub.edu/biblio/ Data/A/0787.pdf

Olesti Vila, O. (2014): Paisajes de la Hispania Romana. La explotación de los Territorios del Imperio. Sabadell, Dstoria Edicions.

Ponsich, M. (1991): Implantation rurale antique sur le Bas Guadalquivir. Tomo IV. Madrid, E. de Boccard.

Poux M.; Debize, T.; Clément, B.; Collet, A.; Gilles, A.; Guillaud, L.; Latour-Argant, C.; Prioux, A. y Carrato, C. (2011): "Le «vin du Triumvir» à Lyon. Témoignages archéologiques et littéraires d'une production de vin sur le territoire colonial de Lugdunum". Gallia 68-1: 13-91. http://www.academia. edu/2125165/Le_vin_du_Triumvir_\%C3\%A0 L y o n . $\operatorname{arch} \% \mathrm{C} 3 \%$ A9ologiques_et_litt $\% \mathrm{C} 3 \%$ A9raires_d_ une_production_de_vin_sur_le_territoire_colonial_de_Lugdunum

Rackham, H. (translated by) (1971): Pliny. Natural History. Books XVII-XIX. London, William Heineman LTD.

Ruestes i Bitrià, C. (2006): “El poblamiento ibérico y romano en la Layetania litoral (del río Besòs a la Riera de Teià). Aplicación arqueológica de un SIG", en I. Grau Mira (ed.), La aplicación de los SIG en la Arqueología del Paisaje: 227-245. San Vicente del Raspeig, Universidad de Alicante.

Sáez Fernández, A. (1987): Agricultura romana de la Bética I. Sevilla, Universidad de Sevilla.

Sáez Fernández, A. (1995): "El vino en la Bética romana", en J.J. Iglesias Rodríguez (ed.), Historia y cultura del vino en Andalucía: 13-32. Sevilla, Universidad de Sevilla.
Sánchez Alonso, G. (2010): Análisis de la documentación arqueológica de la Villa y el Término Municipal de Rota. Chiclana de la Frontera, Fundación Alcalde Zoilo Ruiz-Mateos.

Segura Mungía, S. y Torres Ripa, J. (2009): Historia de las plantas en el mundo antiguo. Bilbao, Universidad de Deusto. Madrid, Consejo Superior de Investigaciones Científicas.

Sillières, P. (1990): Les voies de communication de l'Hispanie meridionale. Paris, Diffusion de Boccard.

Tchernia, A. (1986): Le vin de l'Italie romaine. Essai d'Histoire économique d'après les amphores. Rome, «L'Erma» di Bretschneider. DOI: https://doi. org/10.3406/befar.1986.1221

Trapero Fernández, P. (2016): "Roman Viticulture Analysis Based on Latin Agronomists and the Application of a Geographical Information System in Lower Guadalquivir". Virtual Archaeology Review 7-14: 53-60. DOI: https://doi.org/10.4995/ var.2016.4481

Trapero Fernández, P. y Mata Almonte, E. (2016): "Entre Portus Gaditanus y Hasta: poblamiento y aprovechamiento de recursos en torno a Laguna Salada", en L. Lagóstena (ed.), Lacus autem idem et stagnus, ubi inmensa aqua convenit (Isid. Etym. 13.19.9). Estudios históricos sobre humedales en la Bética (II): 125-141. Cádiz, Seminario Agustín de Horozco de Estudios Económicos de Historia Antigua y Medieval. http://www.academia.edu/26942958/Entre_Portus_Gaditanus_y_Hasta_poblamiento_y_aprovechamiento_de_recursos_en_torno_a_Laguna_Salada

Wheatley, D. y Gillings, M. (2002): Spatial Technology and Archaeology. The Archaeological Applications of GIS. London, Taylor and Francis.

White, K.D. (1975): Farm equipment of the Roman world. Cambridge, Cambridge University Press. 